Web-Based Monitoring of Piezometers for the U.S. Army Corps of Engineers Moose Creek Dam, North Pole, Alaska

Arthur Gelvin, Christopher Williams, and Stephanie Saari

December 2019

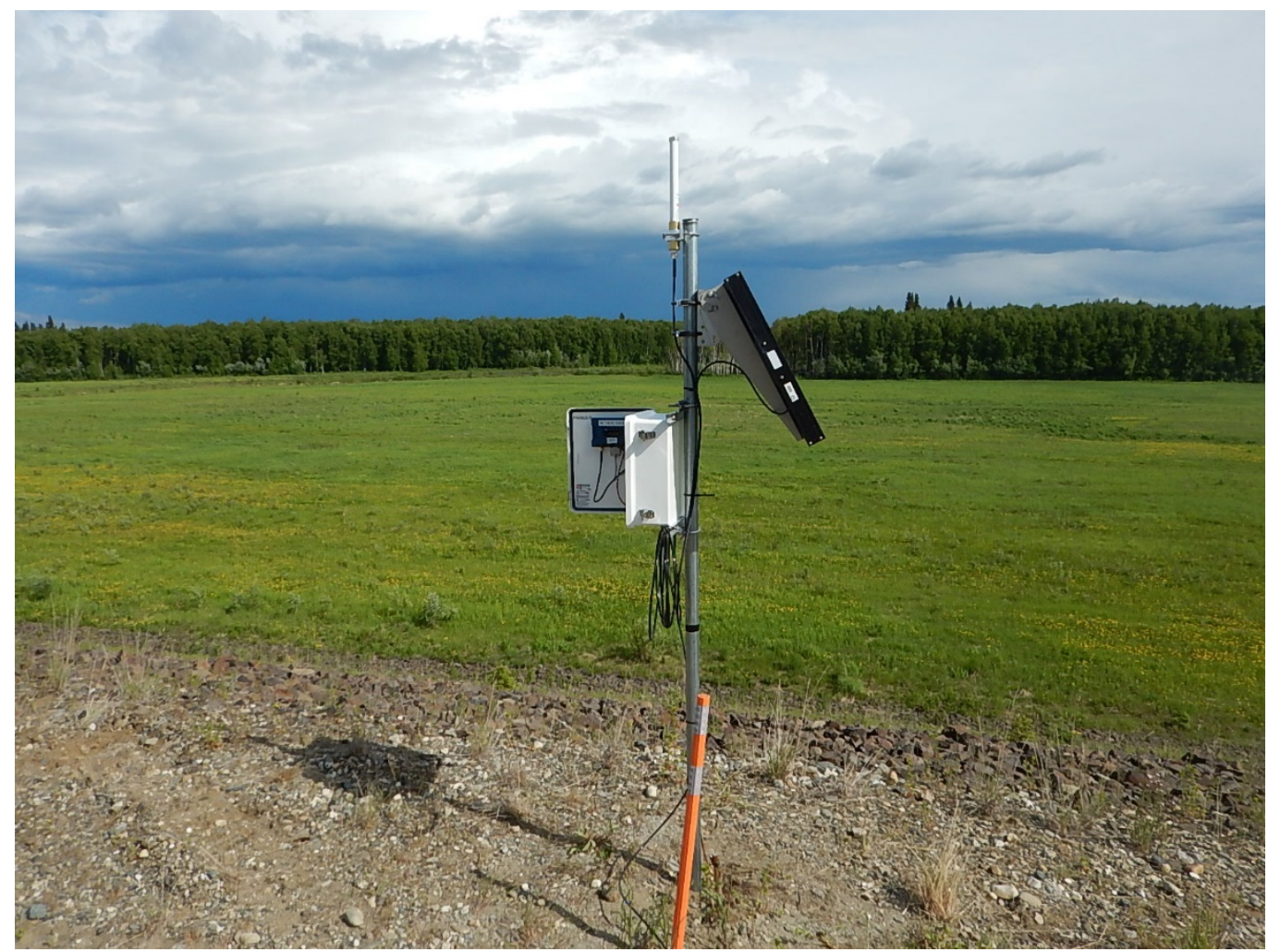


The U.S. Army Engineer Research and Development Center (ERDC) solves the nation's toughest engineering and environmental challenges. ERDC develops innovative solutions in civil and military engineering, geospatial sciences, water resources, and environmental sciences for the Army, the Department of Defense, civilian agencies, and our nation's public good. Find out more at www.erdc.usace.army.mil.

To search for other technical reports published by ERDC, visit the ERDC online library at http://acwc.sdp.sirsi.net/client/default. 


\title{
Web-Based Monitoring of Piezometers for the U.S. Army Corps of Engineers Moose Creek Dam, North Pole, Alaska
}

\author{
Arthur B. Gelvin and Stephanie P. Saari \\ Cold Regions Research and Engineering Laboratory, Alaska Projects Office (CRREL-APO) \\ U.S. Army Engineer Research and Development Center (ERDC) \\ Building 4070, 9th Street \\ Fort Wainwright, AK 99703 \\ Christopher R. Williams \\ Cold Regions Research and Engineering Laboratory (CRREL) \\ U.S. Army Engineer Research and Development Center (ERDC) \\ 72 Lyme Road \\ Hanover, NH 03755-1290
}

Final Technical Report (TR)

Approved for public release; distribution is unlimited.

\footnotetext{
Prepared for U.S. Army Corps of Engineers Alaska District Joint Base Elmendorf-Richardson, AK 99506-089 0

Under Interagency Agreement No. DTFH7016X300008"

Monitored by U.S Army Engineer Research and Development Center Cold Regions Research and Engineering Laboratory 72 Lyme Road, Hanover, NH 03755-1290
} 


\section{Abstract}

The Moose Creek Dam, completed in 1979, is a 7.5-mile long earthen dam located in North Pole, Alaska designed to protect the Fairbanks and North Pole areas from flooding by regulating flow on the Chena River. The earthfilled embankment and a concrete control structure regulates flow with four gated bays. In 2014, two minor flood events took place within 1 month of each other. Flood observations discovered over 1,00o pin/small sand boils downstream of the stability berm, which could signify the initiation of backward erosion and piping with a vertical exit through the boil. The location of greatest distress was mostly within areas of permafrost, some of which have degraded since the dam's construction. During operation, groundwater levels are measured manually at more than 150 piezometers. In 2018, the Corps of Engineers Alaska District tasked the Cold Regions Research and Engineering Laboratory (CRREL) to automate-groundwater levels measurement by installing 21 piezometers. CRREL added instrumentation and monitoring to a network system that aggregates all data. The web-based monitoring system provides a new tool that allows remote Corps personnel to monitor groundwater levels and seepage in areas of significant concern and receive notifications of developing distress during a flooding event.

DISCLAIMER: The contents of this report are not to be used for advertising, publication, or promotional purposes. Citation of trade names does not constitute an official endorsement or approval of the use of such commercial products. All product names and trademarks cited are the property of their respective owners. The findings of this report are not to be construed as an official Department of the Army position unless so designated by other authorized documents.

DESTROY THIS REPORT WHEN NO LONGER NEEDED. DO NOT RETURN IT TO THE ORIGINATOR. 


\section{Contents}

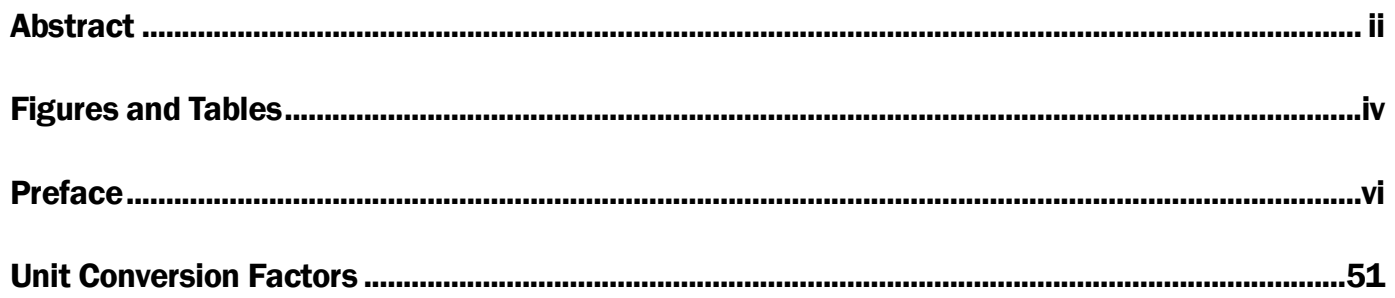

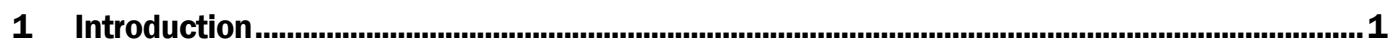

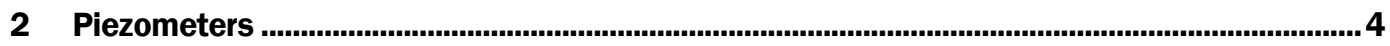

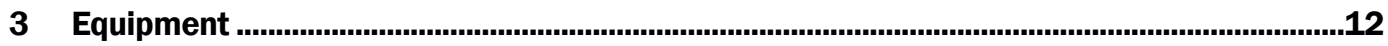

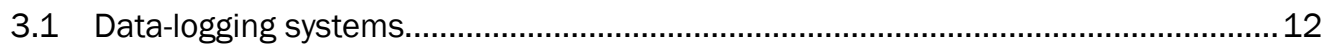

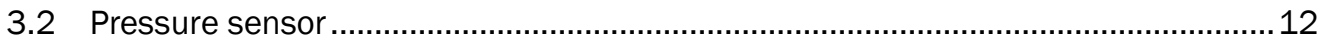

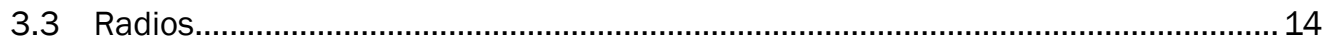

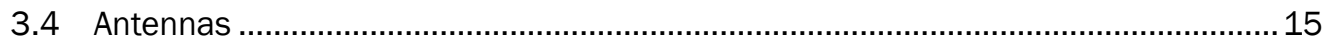

3.5 Radio frequency (Rf) link budget, and fade margin calculation..............................20

3.6 Remote system power budget............................................................................ 23

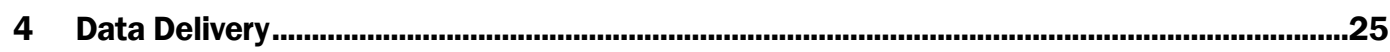

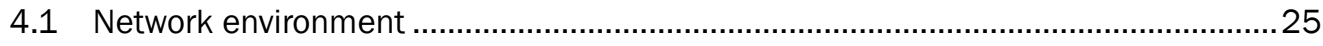

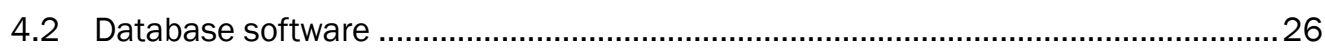

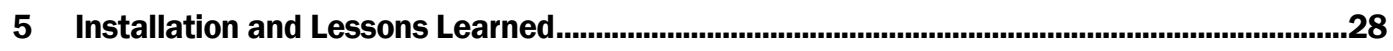

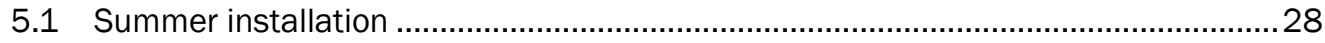

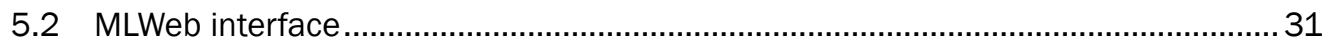

5.3 Piezometer data for cross-sections for the embankment ....................................35

5.4 Piezometers within the control works ................................................................... 41

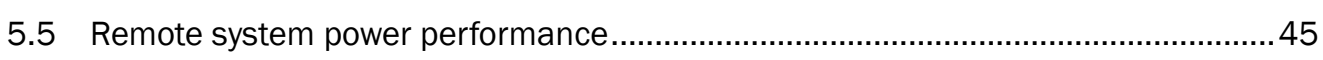

5.6 Adjustments for power budget ............................................................................ 46

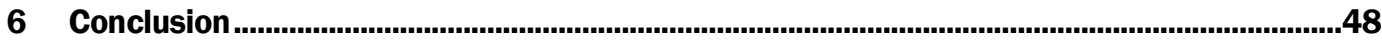

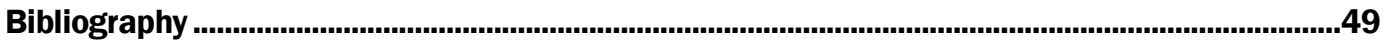

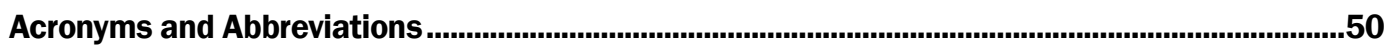

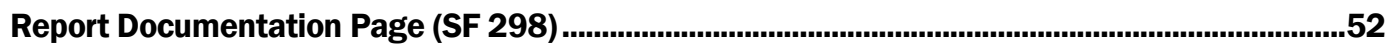




\section{Figures and Tables}

\section{Figures}

1 Location map of the Chena River Lakes Flood Control Project ........................................... 3

2 Basic open standpipe piezometer ................................................................................... 5

3 Piezometers located within the of the Control Works. Piezometers P1 and $\mathrm{P} 4$ are located within the downstream piers on the downstream side of the dam structure, piezometers P2 and P5 are located in the gallery of the dam, and piezometers P3 and P6 are located on top of the dam structure. 6

$4 \quad$ Position of piezometers located along the embankment berm .......................................... 7

5 Piezometer locations along the Chena River Flood Control Project................................... 8

6 An example of frost jacked PVC casing (a), the piezometers located along the top of the embankment are flush to the ground surface, where rocks and dirt can easily be pushed into the piezometer (b) ......................................................... 9

7 Piezometer P3 is flush mounted on the Control Works structure

9 Two pressure sensors, a closed system manufactured by (a) Onset (Onset Computer Corporation n.d.) Computing (b), and an open system with a vent tube by Campbell Scientific, Inc. (Campbell Scientific, Inc. 2018a).

10 A 6-dBd antenna is mounted on a tower at the base station (a), smaller 3$\mathrm{dBd}$ are used at the remote sites that are $0-2$ miles from the base station (b), and smaller whip antennas of 0-dBd are used at stations that are much closer (c)

11 The base station for the radio network resides at the Control Works. Distances are given from the Control Works to each remote cluster of piezometers.

12 Distance information for piezometer clusters, P-392 (P-394, and P-513), P-386, and P-508 are located at the top of the embankment

13 Distance information for three piezometer clusters, P-455 and P-458 are located at the top of the embankment

System Gain-Loss Profile for a Link Budget

Network configuration.

17 View of a cross-section with three piezometers (a), with a station at the crest of the embankment (b), the toe of the embankment (c), and at the toe of the stability berm (d).

18 Six piezometers are located within the Control Works structure. For the top piezometers, the sensor cable was run along the expansion joint (a) to a location away from bailing operations ( $b$ and $c$ ). The base station is located within the Control Works (d), and two piezometers are in the gallery of the Control Works (e and f)

19 Main data page for MLWeb®

20 A cross-section located at Station 360+00 with current data shown for piezometers P451, P454, and P455

21 An example of data display showing water elevation and groundwater temperature. 
22 Piezometers at Station $307+50$ as compared to the USGS stream gage ........................36

23 Piezometers at Station $360+00$ as compared to the USGS stream gage.........................37

24 Piezometers at Station 398+00 as compared to the USGS stream gage.........................38

25 Piezometers at Station $434+00$ as compared to the USGS stream gage.........................39

26 Piezometers at Station $453+50$ as compared to the USGS stream gage........................40

27 Piezometers at Station $406+55$, which is located within the Control Works, as compared to the USGS stream gage ...........................................................42

28 Piezometers at Station 407+71, located within the Control Works, as compared to the USGS stream gage................................................................................43

29 Piezometers within the Control Works are frozen during the winter.................................44

30 Piezometer P458 battery performance ....................................................................45

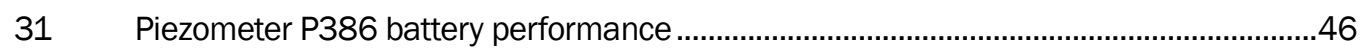

32 Yearly solar radiation for Fairbanks, AK (2009 - 2018).................................................. 47

\section{Tables}

$1 \quad$ Elevation data for instrumented piezometers.................................................................11

2 Units of measurement use to express the ratio of one value of power to

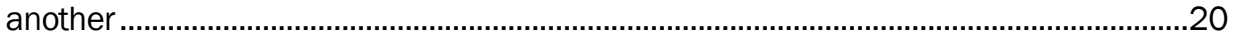

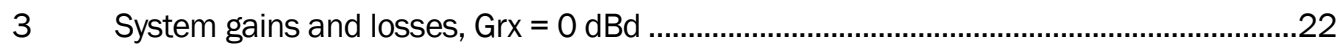

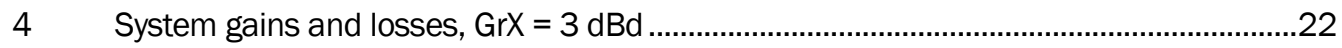

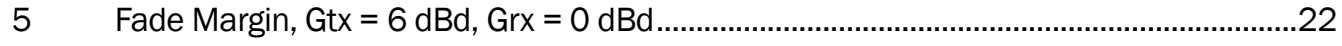

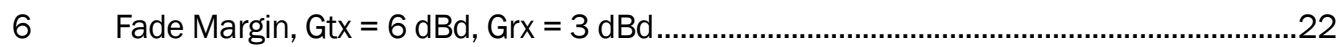

7 Schedule for activating the radio transceiver to account for change in the

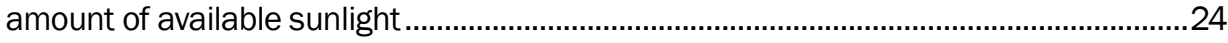

8 Recommended settings for collecting data based on time of year .................................4 


\section{Preface}

This study was conducted for the U.S. Army Corps of Engineers Alaska District under Interagency Agreement No. DTFH7016X300008.

This work was performed by the Engineering Resources Branch of the Research and Engineering Division. U.S. Army Engineer Research and Development Center, Cold Regions Research and Engineering Laboratory (ERDC-CRREL). At the time of publication, Mr. Jared Oren was acting Division Chief of the Research and Engineering Division; Dr. Caitlin Callaghan was acting Chief of Engineering Resources Branch; and Mr. Mark Moran was the Technical Director for Arctic Infrastructure Technical Area. The Deputy Director of ERDC-CRREL was Mr. David B. Ringelberg and the Director was Dr. Joseph L. Corriveau.

Special thanks are owed to Ann Staples and Chris Donnelly, CEERD-RRE, and to the entire ERDC Research and Development Environment (RDE) network staff, especially Daniel Sirois, Mike Long, David Ciciora, Jarred Taylor, and Sierra Wells for their support.

COL Teresa A. Schlosser was the Commander of ERDC, and Dr. David W. Pittman was the Director. 


\section{Introduction}

\subsection{Background}

The primary purpose of the Chena River Lakes Flood Control Project, which was completed in 1979, is to protect the Fairbanks and North Pole areas from flooding by the Chena River. The main component of the project is the Moose Creek Dam, located approximately 17 miles $(27 \mathrm{~km})$ east of Fairbanks, Alaska near the town of North Pole. The project includes three major components: (1) the concrete and steel Control Works structure located on the Chena River with moveable gates, (2) a 7.5-mile $(12 \mathrm{~km})$ long, $50 \mathrm{ft}(15.24 \mathrm{~m})$ tall earthen structure built across the floodplain of the Chena River that functions as a dry dam, and (3) the 21-mile $(33.8 \mathrm{~km})$ long Tanana River Levee with its associated protective groins, that runs along the right bank of the Tanana River between the floodway and the mouth of the Chena River. The first two components, the Control Works and dry dam embankment, work together to regulate flood flows in the Chena River. By lowering the gates within the Control Works, water is impounded behind the earthen dam during high water events, which allows for a controlled release of water through the Chena River. During extreme flood events, excess flows are diverted through the ungated floodway into the Tanana River. As part of the gravel dry dam embankment, a thinner grave stability berm was installed on the downstream side of the embankment, and an impervious silt blanket was installed on the upstream side of the embankment. Both were designed to slow down groundwater infiltration under the embankment during high water events.

Two relatively minor flood events took place within 1 month of each other in the summer of 2014. Nearly 1,000 pin/small sand boils were discovered downstream of the stability berm during flow observations. The location of greatest distress was mostly within areas of permafrost, some of which have degraded since the construction of the flood control project, which could signify the initiation of backward erosion and piping with a vertical exit through the boil. Piezometer wells are located along the dam to monitor embankment water levels, thereby improving the ability to detect developing dam safety issues. These piezometers are spaced far apart along the 7.5 mile long dam embankment; this spacing makes manual data collection less than optimal, especially during an operational event (Figure 1). 
In 2018, the Corps of Engineers Alaska District (the AK District) decided to automate the data collection by logging and posting the piezometer data through a networked system that would aggregate the data in a central location. This central location will be a web-based monitoring system and will provide the AK District with real-time remote access to dam safety data that will improve monitoring capabilities and data accuracy.

\subsection{Objective}

The objective of this work was to help the AK District to automate their data collection by selecting and configuring a data-logging system that will accurately log and post piezometer data through a networked system, and that will aggregate the data in a central location.

\subsection{Approach}

To configure a system that would meet the AK District's need for reliable data collection, researchers (1) selected a data-logging system, (2) calculated the power consumption of each component, and (3) determined the frequency of the data to be collected. 


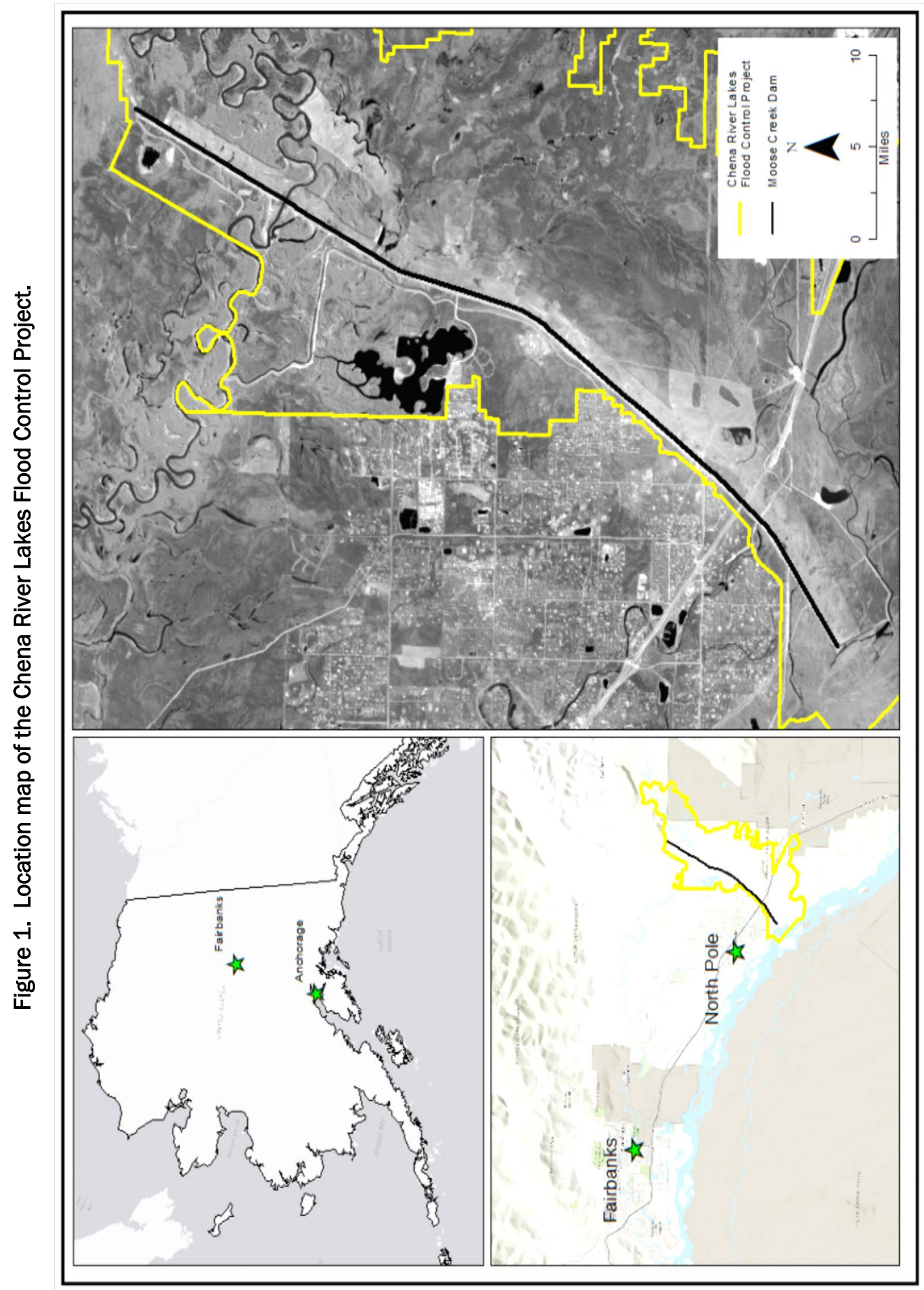




\section{Piezometers}

A piezometer is used to measure the static pressure or head (elevation to which water will rise in an open standpipe) of the groundwater at a specific point. The piezometers located at the Moose Creek Dam are the basic open standpipe style, which is the simplest type to install (Wilson and Squier 1969). This type of piezometer varies mainly in diameter, the piezometers here typically consist of 2-in. diameter polyvinyl chloride (PVC) pipe that is placed in a borehole at the desired depth, where the bottom sections of PVC have slots to allow groundwater to flow into the pipe. A much larger well casing, such as a 4-in. steel pipe or a 4-in. square casing, is placed over the PVC to provide some protection to the piezometer (Figure 2). Within the project area, 150 piezometers are spaced along the 7.5 mile long dam embankment. Historically, during operational events, the water levels at each location have been measured manually, once a day, using a water level indicator. Collecting manual measurements is a time-consuming effort and does not capture the fluctuations of the water table during a flood event. This process can be automated with the use of an electronic sensor placed at the bottom of the PVC pipe that monitors the liquid pressure of the column of water within the PVC. Twenty-one piezometer locations were chosen to be instrumented; six locations are within the Control Works structure (Figure 3) and 15 locations are along the gravel embankment (Figures 4 and 5). 
Figure 2. Basic open standpipe piezometer.

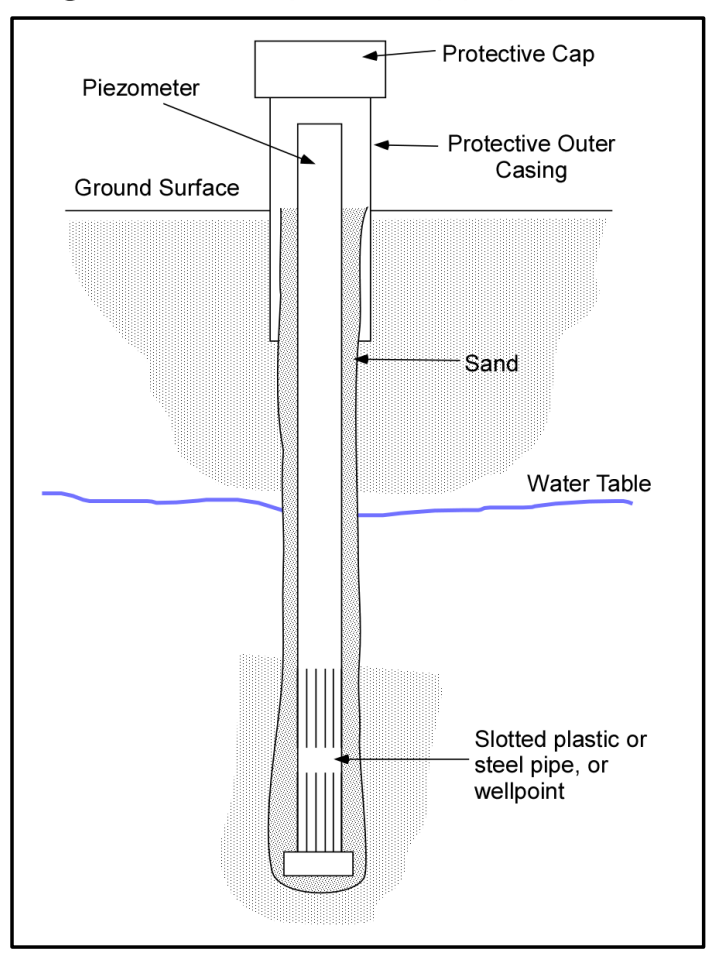

The initial investigation of the piezometers and their conditions revealed that previous manual measurements were not kept; the most recent measurements go back just a few years. Without any historical records that would indicate the fluctuations that the water column in each piezometer would see in a typical event, it was decided to place the sensor at the bottom of each piezometer to ensure the pressure transducer remained within the water column. There are no recent measurements of the actual depth of the piezometers. Furthermore, cable length and selection of the transducers was based on using the as-built information from the bore logs. In some cases, the actual total depth of the piezometers differed from what the bore logs indicated. Some of this could be explained by frost jacking of the PVC pipe (Figure 6a), a buildup of sediment at the bottom of the pipe, or debris entering the pipe due to the protective outer casing being flush to the ground surface (Figure 6b). Although nearly all of the piezometers have a protective well casing that has a cap or lid, there are no well caps to close off the PVC pipe to prevent debris from falling into the piezometers. 
Figure 3. Piezometers located within the of the Control Works. Piezometers P1 and P4 are located within the downstream piers on the downstream side of the dam structure, piezometers P2 and P5 are located in the gallery of the dam, and piezometers P3 and P6 are located on top of the dam structure.

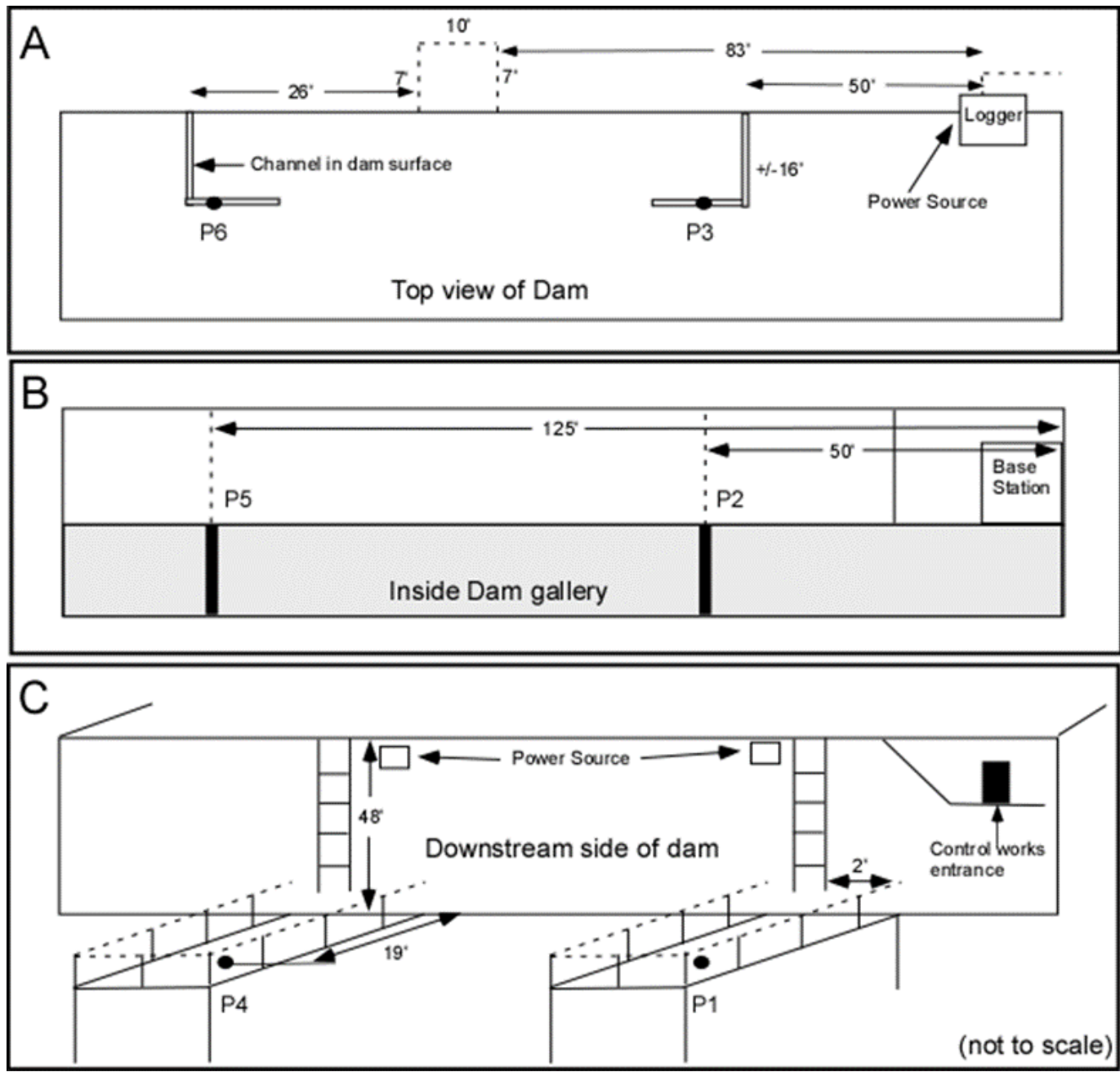




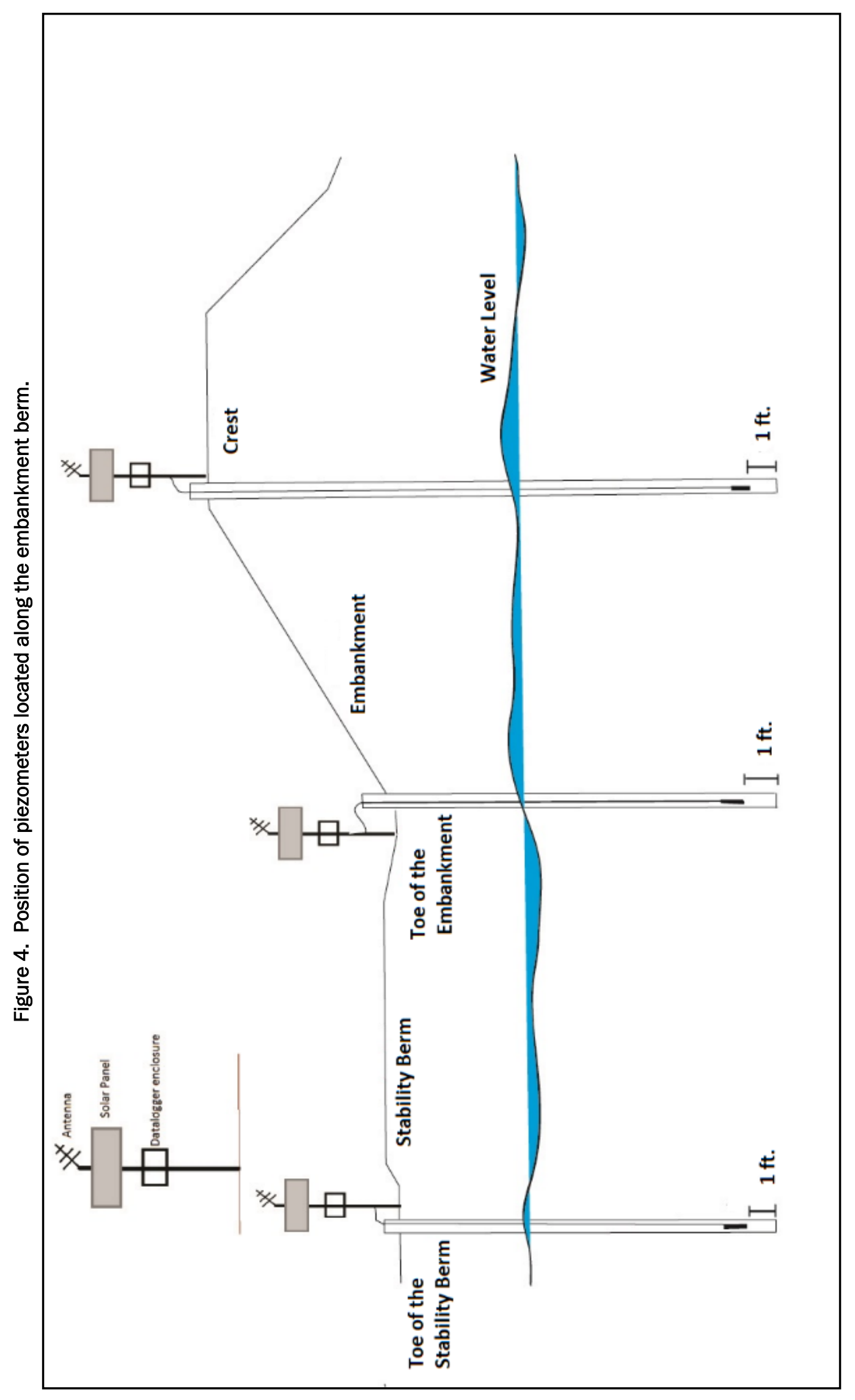


Figure 5. Piezometer locations along the Chena River Flood Control Project.

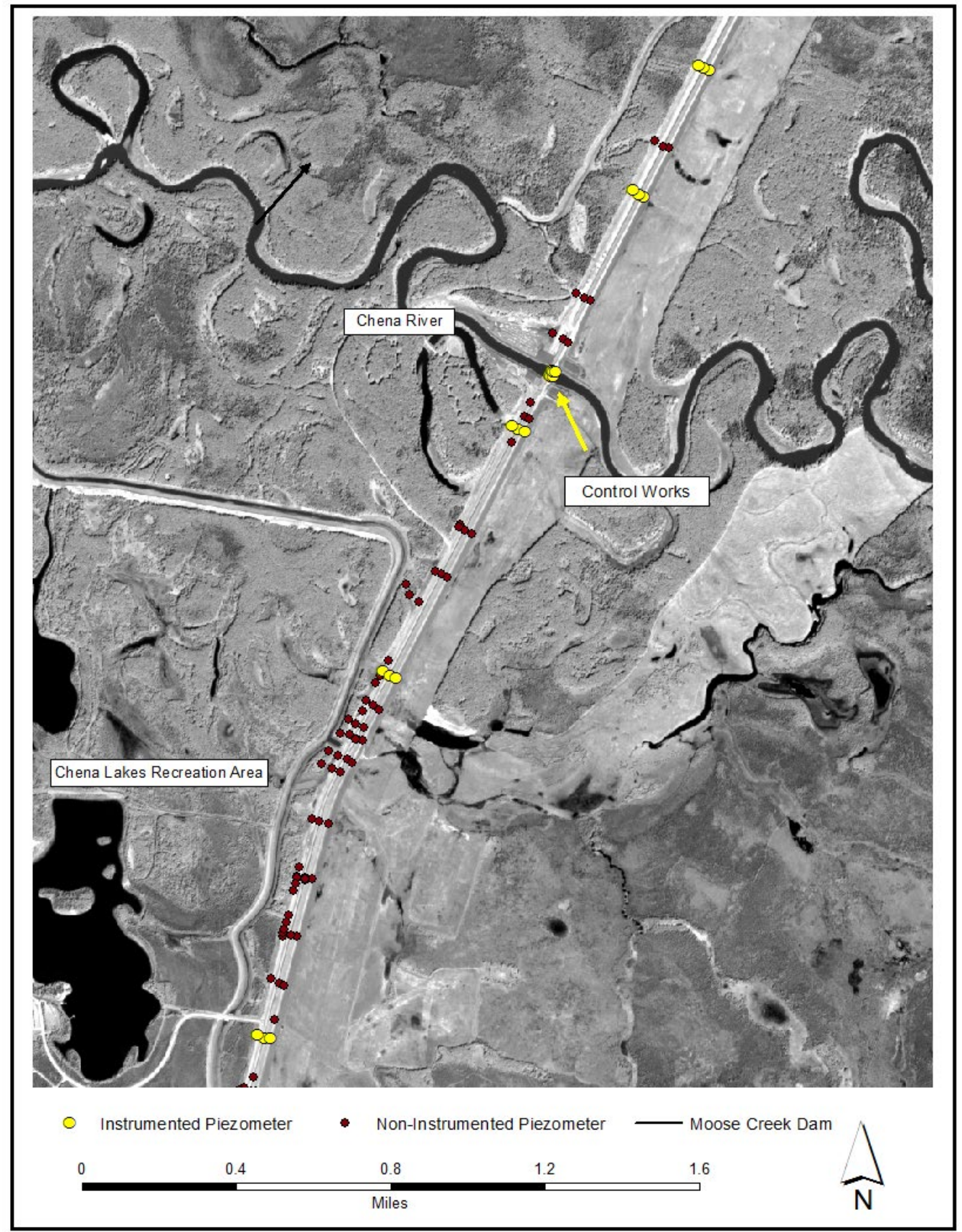


Figure 6. An example of frost jacked PVC casing (a), the piezometers located along the top of the embankment are flush to the ground surface, where rocks and dirt can easily be pushed into the piezometer (b).

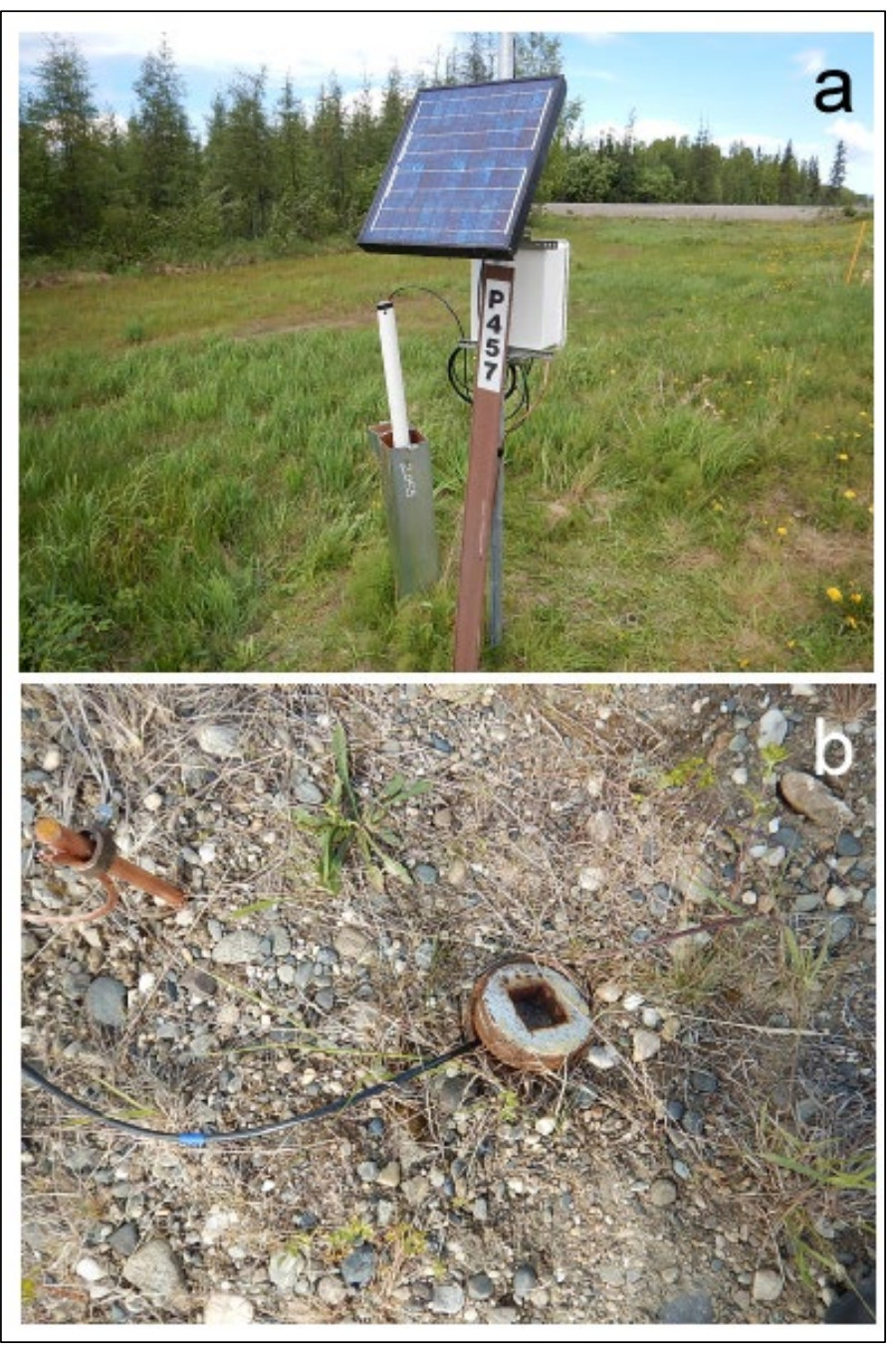

There are three piezometers within the Control Works structure (P1, $\mathrm{P}_{3}$, and P6) that were measured 10 to $15 \mathrm{ft}$ ( 3 to $4.5 \mathrm{~m}$ ) above the as-built depth. Bailing operations, i.e., the removal of debris blocking the flood gates, occurs on top of the Control Works. It is assumed that debris, such as dirt, wood particles, sand etc., falls into piezometers $\mathrm{P}_{3}$ and $\mathrm{P} 6$ (Figure 7). $\mathrm{P}_{4}$ is located at the base of the dam near the water surface and there is evidence that debris could have entered the piezometer. The Dam Operator made efforts to clear the debris from the piezometers; $\mathrm{P}_{1}$ and $\mathrm{P}_{3}$ appear to be successfully cleared. P6, however, had other issues, either because a large blockage was preventing the sensor from reaching the bottom of the piezometer or because the PVC pipe itself may have been damaged. 
Figure 7. Piezometer P3 is flush mounted on the Control Works structure.

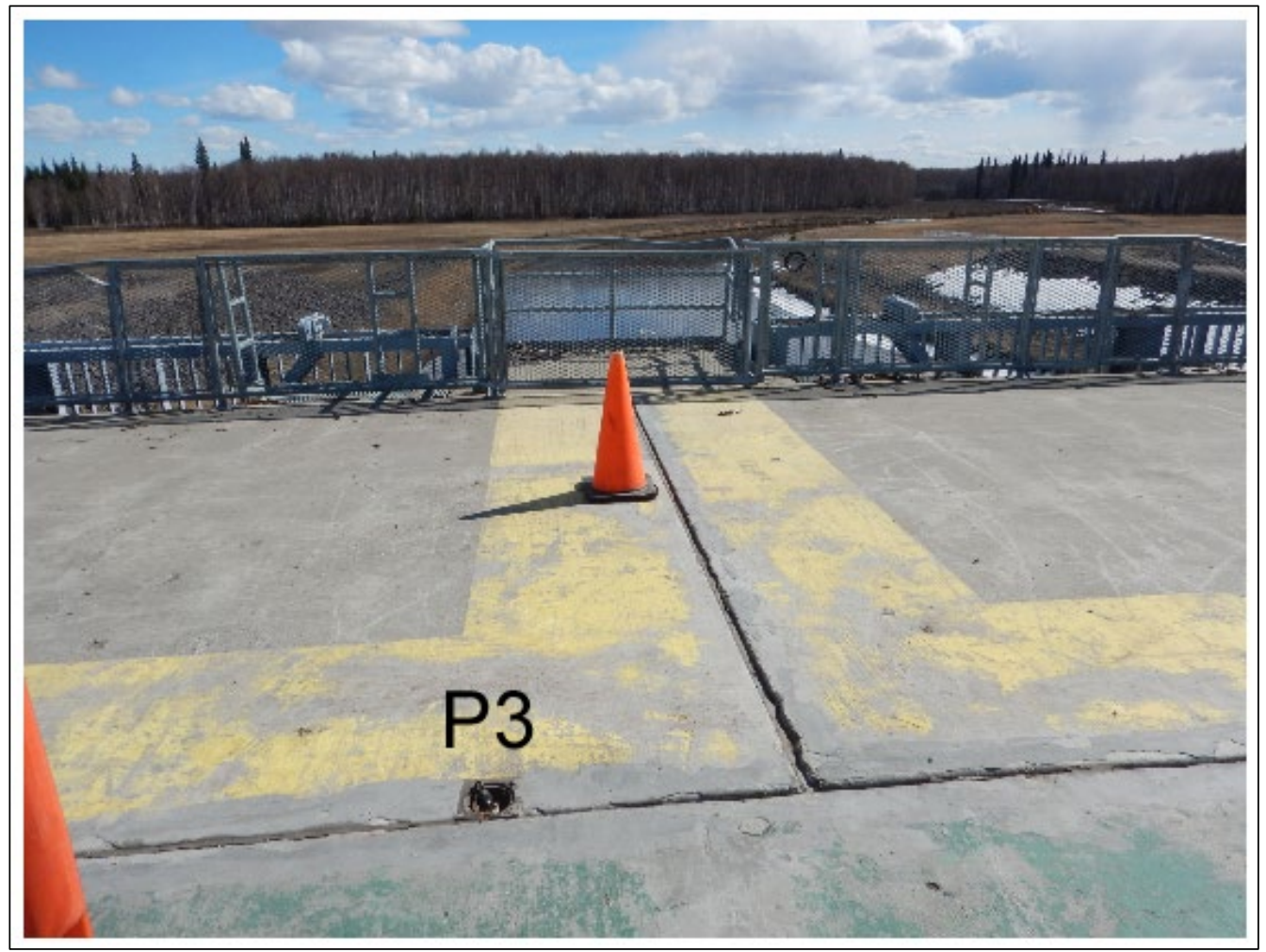

Table 1 lists information for each piezometer; elevation data for the casing and ground was updated in 2017. The "stickup" refers to the amount of the PVC above the ground surface. All measurements for the depths are based on the top of the PVC casing (TOC). Measurements still need to be verified due to the efforts to clear the debris from the piezometers. The PVC casing located at P457 appears to be moving; this is likely due to the freeze thaw cycles, which would require a periodic check to track. Since the elevation of the water levels is based on the top of casing, a change in elevation of the PVC will change the depth of the sensor location. 
Table 1. Elevation data for instrumented piezometers.

\begin{tabular}{|c|c|c|c|c|c|c|}
\hline \multirow[b]{2}{*}{$\begin{array}{l}\text { Well } \\
\text { ID }\end{array}$} & \multicolumn{2}{|c|}{ Elevation (ft) } & \multirow[b]{2}{*}{$\begin{array}{l}\text { Stickup } \\
\text { (ft) }\end{array}$} & \multirow[b]{2}{*}{$\begin{array}{l}\text { As-built } \\
\text { Depth (ft) }\end{array}$} & \multirow{2}{*}{$\begin{array}{l}\text { Actual Total } \\
\text { Depth from } \\
\text { TOC (ft) }\end{array}$} & \multirow{2}{*}{$\begin{array}{l}\text { Depth of } \\
\text { Sensor from } \\
\text { TOC (ft) }\end{array}$} \\
\hline & Casing & Ground & & & & \\
\hline $\mathrm{P} 1$ & 503.24 & 503.10 & 0.14 & 33.3 & $23.04^{*}$ & 21.97 \\
\hline P2 & 521.1 & 521.10 & 0.00 & 51.2 & 50.55 & 36.4 \\
\hline P3 & 531.87 & 531.80 & 0.07 & 61.9 & 60.80 & 59.89 \\
\hline P4 & 503.03 & 503.03 & 0.00 & 33.3 & $26.12^{\dagger}$ & 24.97 \\
\hline P5 & 521.1 & 521.10 & 0.00 & 51.2 & 50.63 & 43.01 \\
\hline P6 & 531.73 & 531.73 & 0.00 & 61.9 & $45.96 \neq$ & 46.3 \\
\hline P271 & 504.51 & 501.13 & 3.38 & 23.7 & 25.85 & 24.83 \\
\hline P351 & 503.65 & 501.18 & 2.47 & 21.1 & 23.35 & 22.33 \\
\hline P386 & 533.82 & 533.77 & 0.06 & 60.0 & 53.10 & 52.21 \\
\hline P388 & 511.51 & 507.96 & 3.55 & 36.3 & 38.48 & 37.48 \\
\hline P392 & 534.15 & 534.00 & 0.15 & 53.9 & 52.73 & 51.73 \\
\hline P394 & 512.10 & 509.45 & 2.65 & 27.2 & 29.13 & 28.21 \\
\hline P451 & 495.43 & 492.15 & 3.28 & 28.5 & 30.81 & 29.84 \\
\hline P454 & 502.70 & 500.78 & 1.92 & 25.2 & 24.14 & 23.13 \\
\hline P455 & 532.24 & 532.09 & 0.15 & 59.1 & 51.78 & $51.24 *$ \\
\hline P457 & 499.61 & 495.33 & 4.28 & 12.8 & 25.92 & 24.95 \\
\hline P458 & 530.37 & 530.28 & 0.09 & 57.5 & 56.21 & 55.08 \\
\hline P508 & 531.82 & 531.69 & 0.13 & 62.5 & 62.89 & 62.02 \\
\hline P509 & 506.31 & 503.45 & 2.86 & 27.3 & 30.52 & 29.52 \\
\hline P511 & 504.03 & 500.89 & 3.14 & 27.5 & 30.75 & 29.2 \\
\hline P513 & 505.70 & 502.67 & 3.04 & 28.0 & 31.19 & 29.92 \\
\hline \multicolumn{7}{|c|}{ Source of elevation datum: NAVD 88 (NGS 2018) } \\
\hline \multicolumn{7}{|c|}{$\begin{array}{l}\text { *Actual depth was measured before efforts were made to remove debris from the piezometer. } \\
\text { †Blockage or debris within the piezometer. } \\
\text { †There appears to be a blockage or damage to the PVC }\end{array}$} \\
\hline
\end{tabular}




\section{Equipment}

\subsection{Data-logging systems}

Available data-logging systems were investigated to determine what systems were applicable and how they would meet the project requirements. Due to the widely spread locations of the piezometers, power for the instrumentation will be provided by a combination of a 12-volt direct current (Vdc) battery and a solar panel. The project location is semi-remote, where the instrumentation must be low power, have accurate logging capability, and be expandable and configurable for additional instrumentation. Because of the cold winter air temperatures, the logger instrumentation also needs to be rated for colder temperatures. The selected dataloggers are manufactured by Campbell Scientific. The compact CR30o (Campbell Recorder) datalogger (Figure 8a) is used at the remote locations, and the larger, more powerful CR6 datalogger (Figure 8b), which has Ethernet capabilities, serves as the base station. Both systems are compact measurement and control devices that are ideal for establishing a radio control network. The 17 loggers in use communicate data to the CR6 using the Campbell Scientific PakBus networking system protocol, in which each logger is assigned a unique address. A PakBus network allows simultaneous communications between the datalogger and other devices, enables peer-to-peer communication without a computer, and supports automatic route detection and selection (Campbell Scientific, Inc. 2018b).

Figure 8. The CR300 datalogger is used at the remote sites (a) and CR6 is at the base station (b).

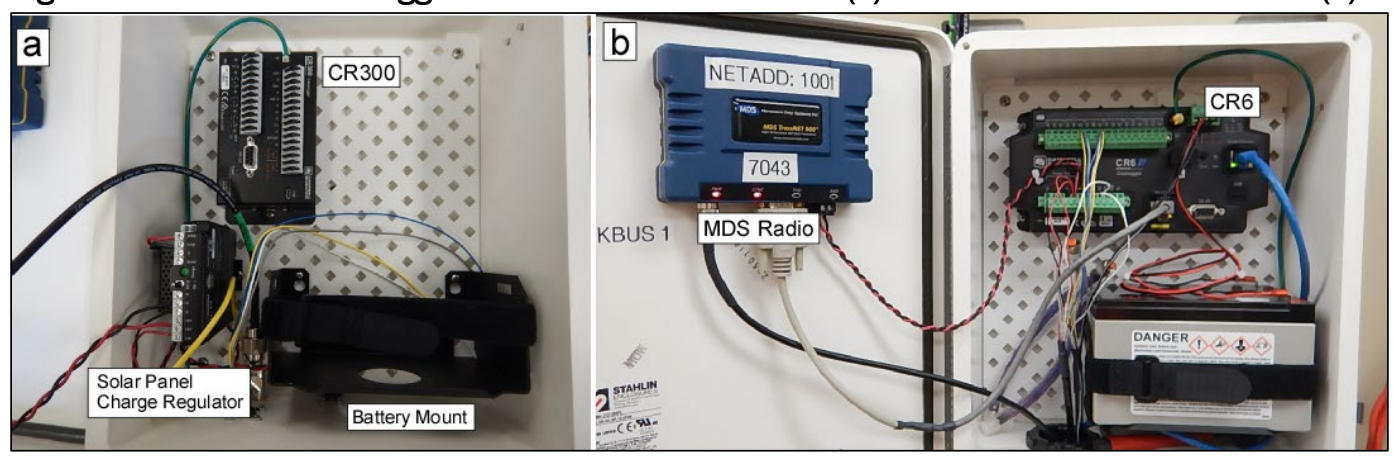

\subsection{Pressure sensor}

A pressure transducer is a sensor that converts applied pressure into an electrical signal. There are many different types of pressure transducers, 
including a voltage/current output transducer, a digital output transducer, and a capacitive pressure transducer, to name a few. In all types of transducers, the physical deformation of an elastic material, acting as a diaphragm, is converted into an electrical signal. This is accomplished by measuring the proportional change of an electrical resistor as the pressure applied to the diaphragm (and the electrical resistance) changes. Once the different methods convert the measured pressure into an electrical signal, the resultant pressure also must be adjusted to compensate for the weight of the atmosphere; the type of process used can vary depending on whether the sensor used is a closed or a vented system.

As atmospheric pressure fluctuates, it influences the pressure on the transducers, resulting in fluctuating water level measurements. In a closed transducer system (Figure 9a), the sealed transducer requires compensation to account for the changes in the atmosphere. To do this, a separate sensor is used to record the atmospheric barometric pressure; the transducer reading is subtracted from the atmospheric barometric pressure to get the actual water pressure. Barometric changes in the atmosphere can vary; barometric pressure readings that are recorded within 10 miles $(15 \mathrm{~km})$ of the logger can be used without significantly degrading the accuracy of the compensation (Onset Computer Corporation 2018). However, depending on the accuracy needed, multiple barometric sensors may be required to account for micro-changes in the atmosphere.

Figure 9. Two pressure sensors, a closed system manufactured by (a) Onset (Onset Computer Corporation n.d.) Computing (b), and an open system with a vent tube by Campbell Scientific, Inc. (Campbell Scientific, Inc. 2018a).

a
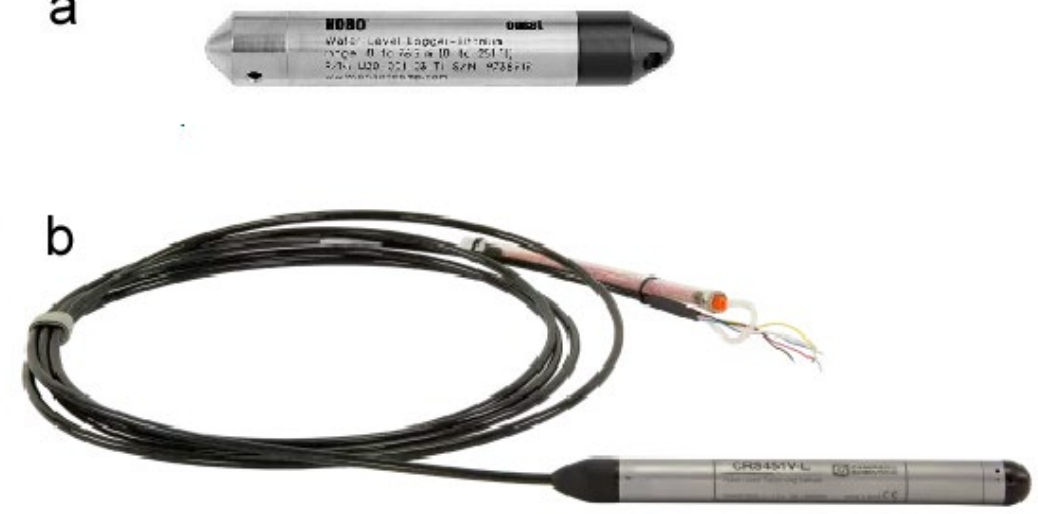
The sensor chosen for this project is the Campbell Scientific CS451 Submersible Pressure Transducer (Figure 9b). This transducer is a vented system that provides pressure and temperature measurements. The CS451 has a vent tube that vents the sensor diaphragm to the atmosphere (Campbell Scientific, Inc. 2018a). This method compensates for atmospheric pressure by equalizing the pressure with the atmosphere, eliminating the need to compensate for changes in barometric pressure. As with all solutions, there can be some drawbacks to the vented system. Care must be taken to prevent the vent tube from kinking. A desiccant pack is used at the vent tube opening to prevent water vapor from entering the sensor cavity.

\subsection{Radios}

The $902-928 \mathrm{MHz}$ spread spectrum radio was chosen over the traditional licensed radio as means of transmitting data. The spread spectrum radio technology is quite extensively used in the industrial, scientific, and medical industry and thus requires no license to install and operate as a communication device. These devices are typically used in very local lineof-site (LoS) communication networks making them an appropriate technology for the Moose Creek Dam project. The spread spectrum radio technology has one great advantage over the traditional licensed radio. The spread spectrum radio "hops" from channel to channel many times per second using a specific hop pattern that is applied to all 65,000 available network addresses in the radio network. This hopping technique minimizes radio interference from other spread spectrum radios and also provides a level of security from hacking. The model MDS TransNet 900 radio transceiver, manufactured by General Electric, was chosen for the project. This radio has an adjustable transmit power output up to 1 watt (30 dBm), and a receive sensitivity of $-110 \mathrm{dBm}$. The radio network uses the Multiple Address System (MAS). The MAS network enables transparent communications between a central control station (base station) and remote data collection equipment sharing a common network identification number (ID). The base station equipment located at the Control Works structure communicates with the remote sites to the north and south along the embankment over distances no greater than 2 miles $(3.2 \mathrm{~km})$. The radio network is using the LoS type of radio transmission concept, which is a type of radio propagation that requires the transmitting and receiving units be in full view of each other. In locations where there is no LoS, or where the distances are too great for a reliable link, the closest MDS radio will be 
configured as a repeater. The use of a repeater is a method to extend the range of a radio network. The embankment at Moose Creek Dam installation is well suited to set up a LoS radio network. The embankment is flat and cleared of trees and vegetation providing the best environment for radio wave propagation.

\subsection{Antennas}

A reliable link between the MDS radios in the network is created by minimizing all the system component losses in the radio frequency (Rf) link. Antennas, cables, connectors, and radio propagation distance account for these losses. Understanding these losses helps in the proper selection of antennas. At the control structure, 2 miles $(3.2 \mathrm{~km})$ is the greatest transmission distance between radios. Omni unidirectional antennas capable of transmitting and receiving in all directions were chosen as the type of antenna for this project. The omni directional antennas (Figure 10) have many power gain options that assist in radio wave propagations. The gain of an antenna is expressed in units of $\mathrm{dBd}$, which is a measurement of power gain relative to a dipole radiator. At the control structure, short transmissions will require a zero $\mathrm{dBd}$ or three $\mathrm{dBd}$ gain and longer distances will require a 6-dBd gain. As transmission distances increase, point to point directional Yagi antennas will be used. Up to a 30-mile LoS connection is obtainable with high gain Yagi antennas. To help with the selection of the antennas needed, distances are measured from the Control Works, where the base station is located, to the upper piezometer of each cross-section of piezometers (Figure 11). Distances were also measured between each piezometer (Figures 12 and 13). 
Figure 10. A 6-dBd antenna is mounted on a tower at the base station (a), smaller 3$\mathrm{dBd}$ are used at the remote sites that are $0-2$ miles from the base station (b), and smaller whip antennas of 0-dBd are used at stations that are much closer (c).

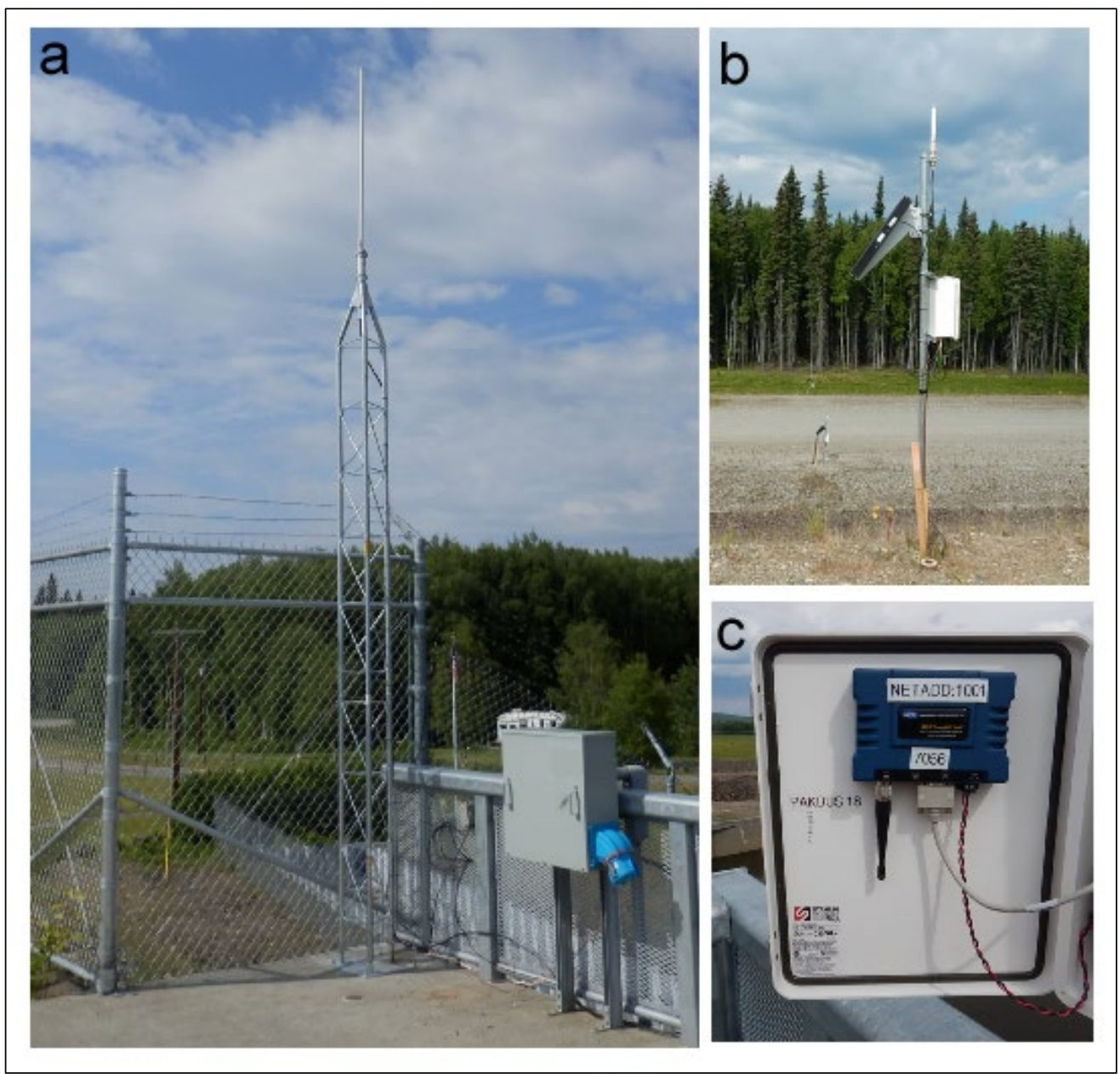




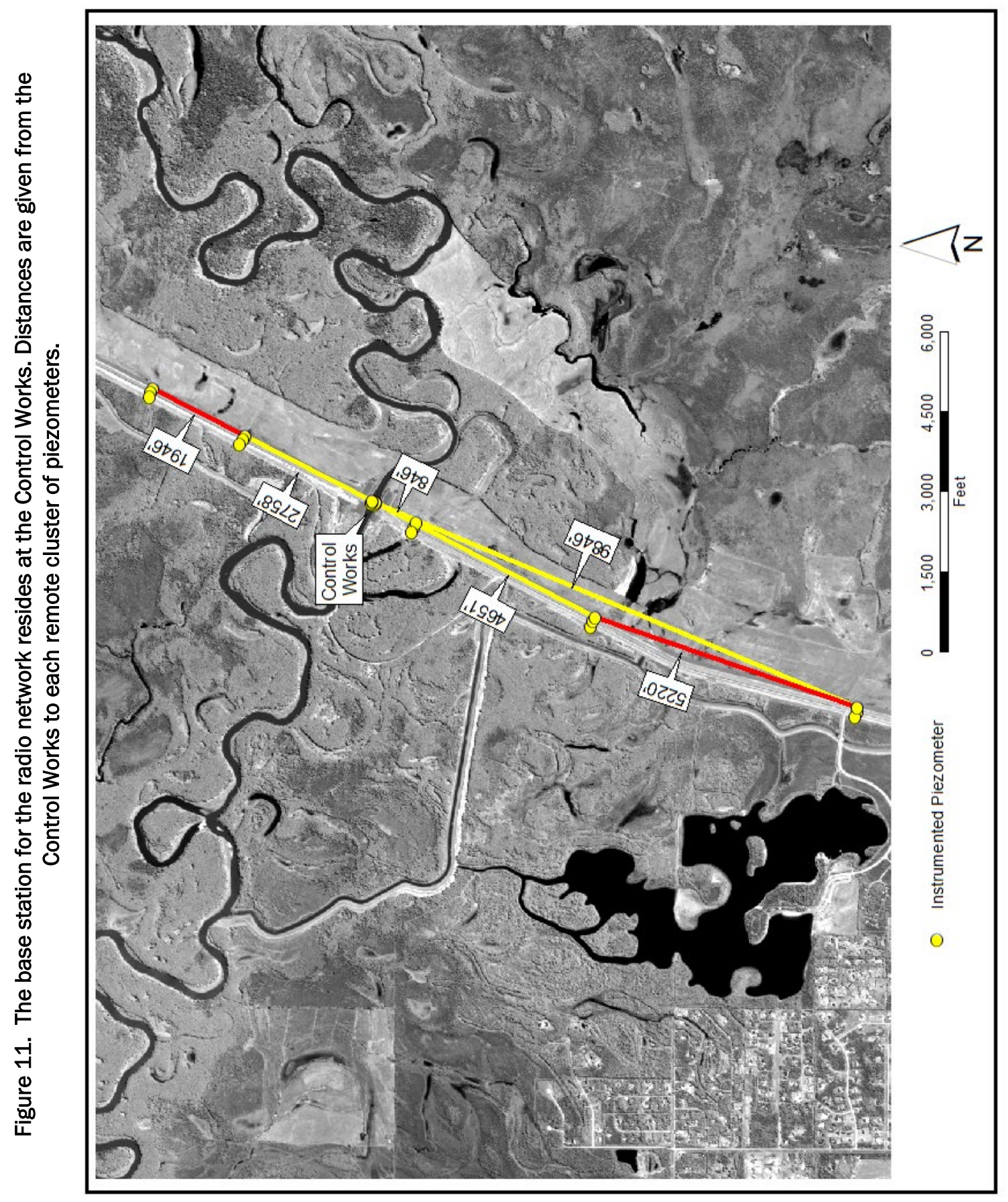




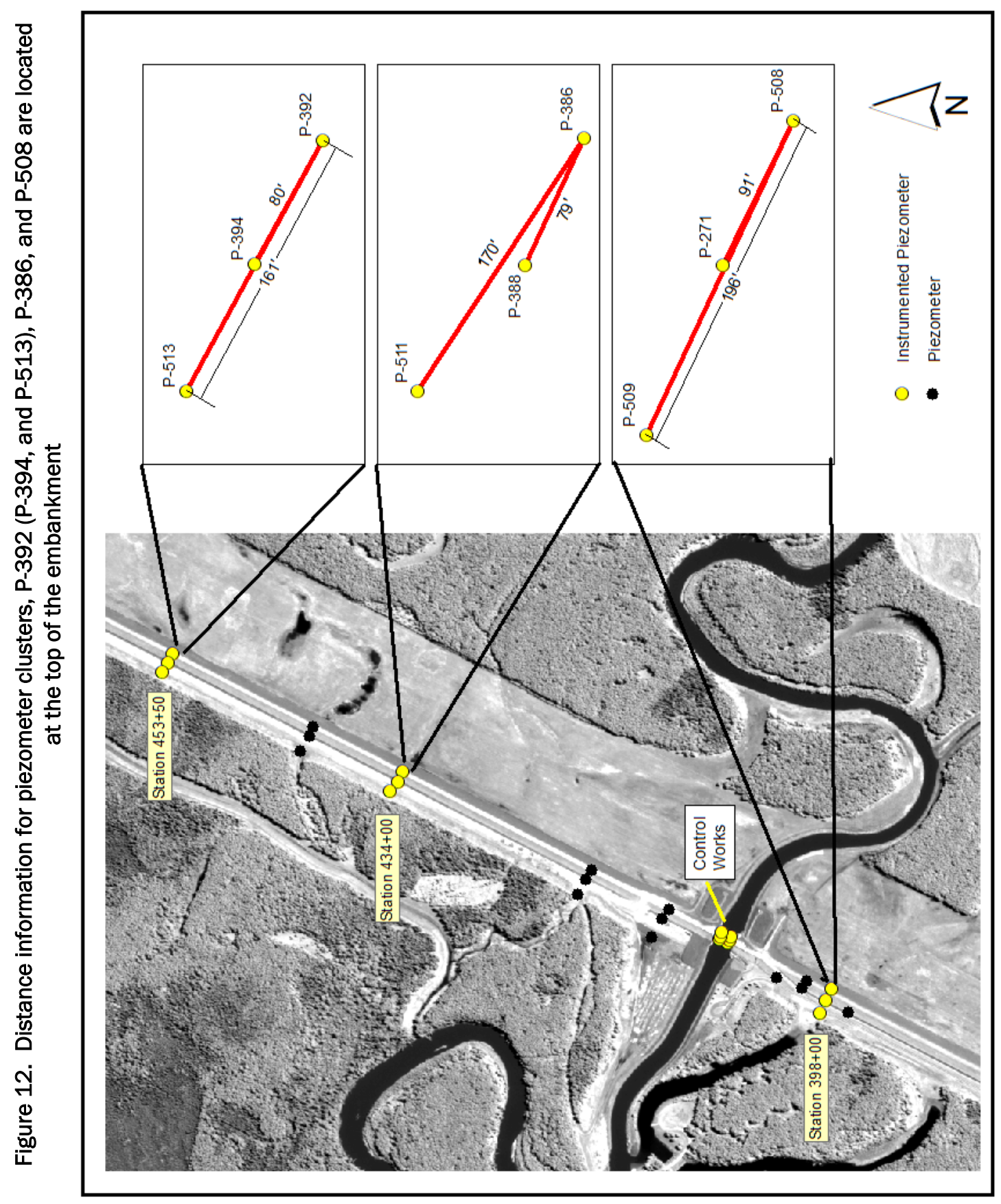




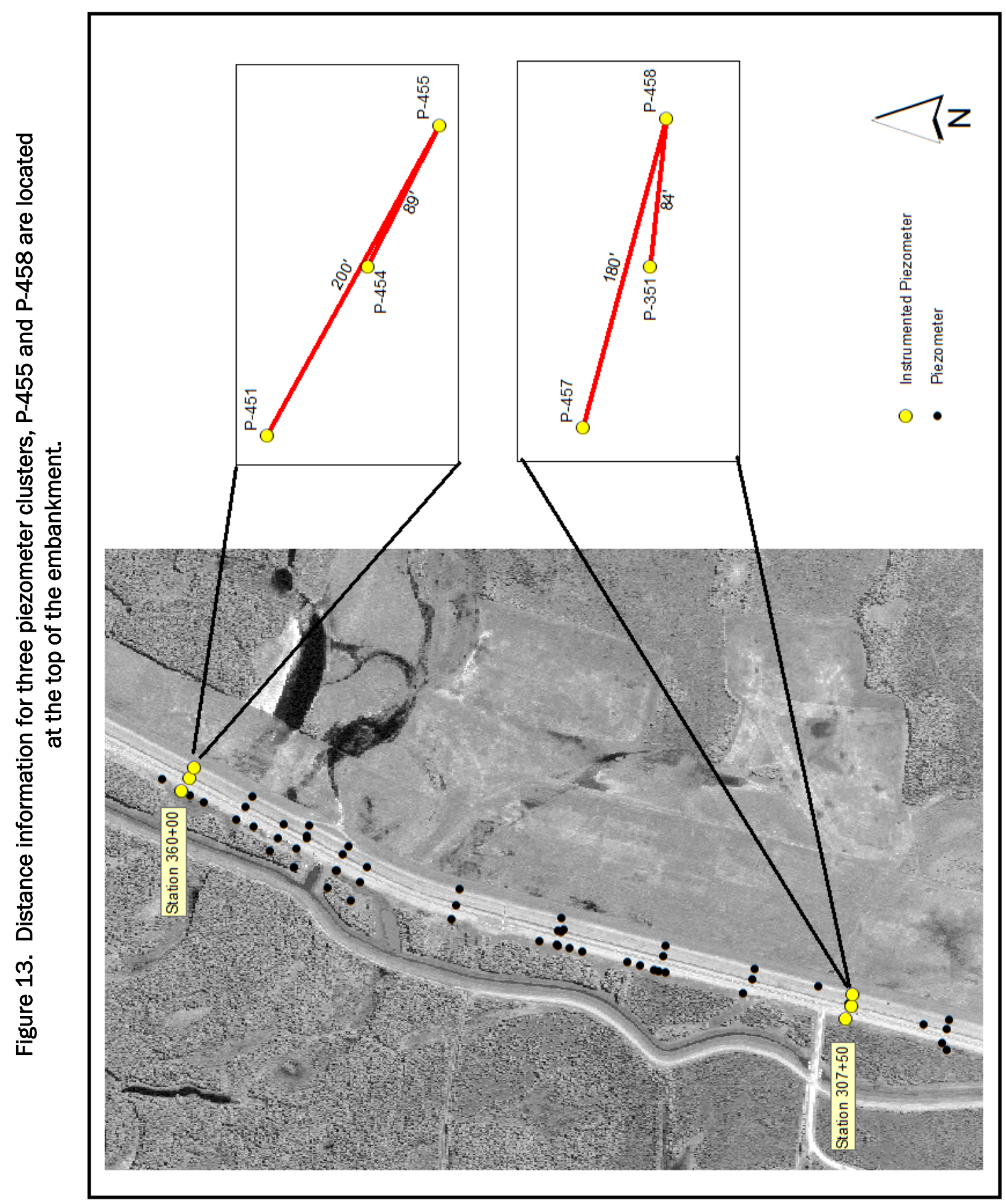




\subsection{Radio frequency (Rf) link budget, and fade margin calculation}

The performance of the radio network is judged by the quality of the transmission. By examining the efficiency of transmission and the signal distortion of the Rf, the Rf gains and losses of the transmitter and receiver equipment (Chu 1948) can be accounted. Figure 14 depicts the System Gain-Loss Profile for a Link Budget of an ideal Rf telemetry link. They are described as:

- $\quad$ Ptx $=$ Transmitter power $(\mathrm{dBm})$

- $\quad$ Ltx $=$ Transmitter system losses $(\mathrm{dB})$

- $\mathrm{Gtx}=$ Transmitter antenna gain $(\mathrm{dBd})$

- Lpath = Propagation losses between transmit and receive antennas (dB)

- $\mathrm{Grx}=$ Receiver antenna gain $(\mathrm{dBd})$

- $\operatorname{Lrx}=$ Receiver system losses $(\mathrm{dB})$

- $\operatorname{Prx}=$ Receiver power $(\mathrm{dBm})$.

The unit $\mathrm{dB}$ is a logarithmic way of describing a ratio, whether the ratio be power, sound pressure, intensity, or several other things. Table 2 lists and briefly defines the units shown above.

Table 2. Units of measurement use to express the ratio of one value of power to another.

\begin{tabular}{|l|l|}
\hline Unit & Definition \\
\hline $\mathrm{dB}$ & Power Gain $(\mathrm{dB})=10 \mathrm{Log}(\mathrm{Rf}$ Output Power / Rf Input Power) \\
\hline $\mathrm{dBd}$ & $\begin{array}{l}\text { A unit of level that indicates antenna gain with respect to a reference dipole } \\
\text { antenna }\end{array}$ \\
\hline $\mathrm{dBm}$ & $\begin{array}{l}\text { A unit of level used to indicate that a power ratio is expressed in decibels }(\mathrm{dB}) \\
\text { with reference to one milliwatt }(\mathrm{mW})\end{array}$ \\
\hline
\end{tabular}


Figure 14. System Gain-Loss Profile for a Link Budget.

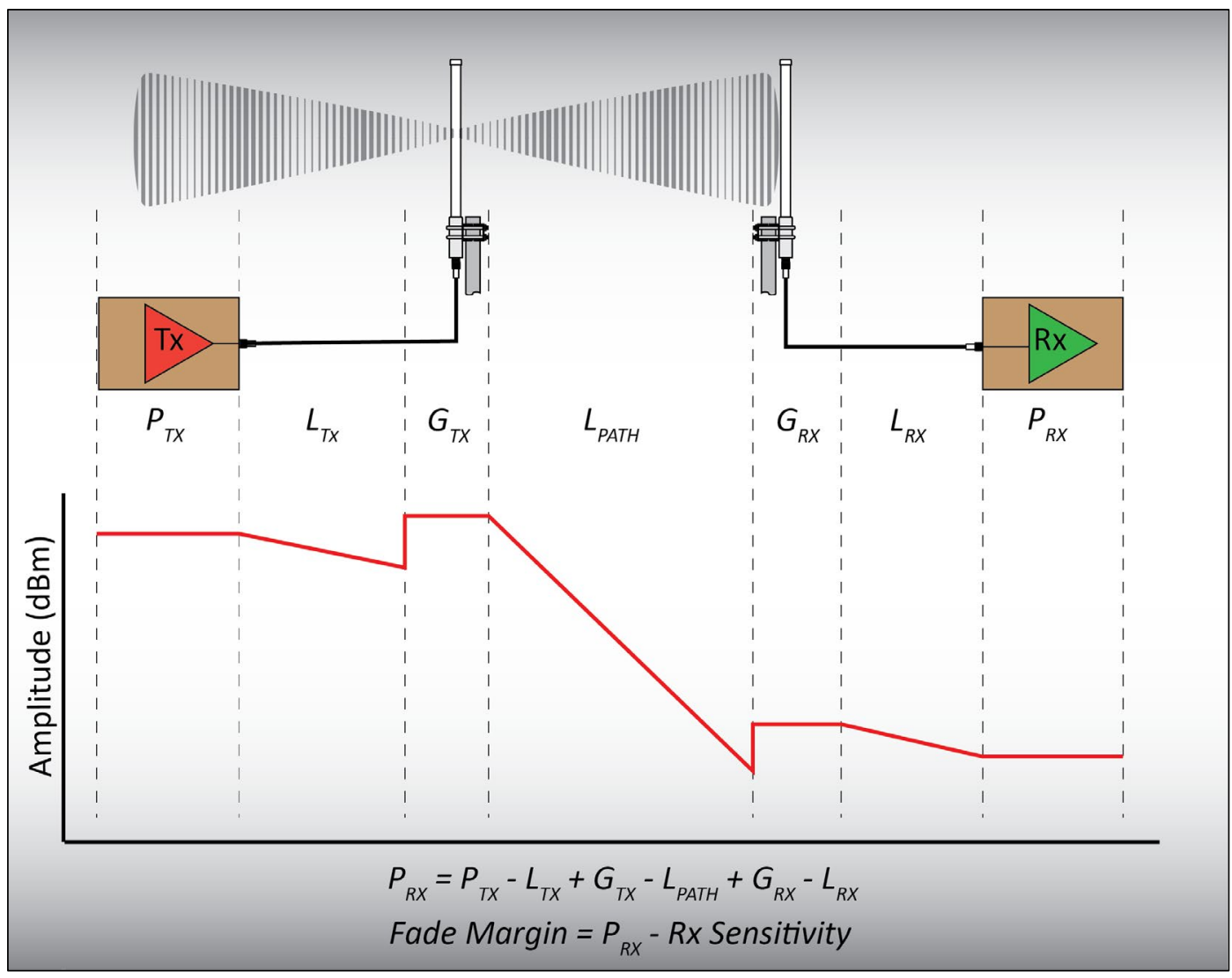

Source: Campbell Scientific, Inc. (2016).

Tables 3 and 4 list the gains and losses of the components used in the Rf telemetry link for the radio network installed at the Moose Creek Dam. To help with the selection of antennas to be used, two Rf link budget scenarios were developed using receiver antenna gains of $\mathrm{o} \mathrm{dBd}$ and $3 \mathrm{dBd}$. A link budget is the level of power available to the receiver and is calculated by knowing the output power capacity of the transmitter and the summation of the system gains and losses between the transmitter and receiver. Tables 5 and 6 list the receiver power and the fade margin relative to the distance between the two antennas. The important parameter in these tables is the fade margin, the higher the $\mathrm{dB}$ value, the more the receiver power (Prx) value will be above the minimum receive sensitivity $(-110$ $\mathrm{dBm}$ ) of the MDS radio. The selection of either the o dBd or $3 \mathrm{dBd}$ antennas will work over a distance of 2 miles $(3.2 \mathrm{~km})$. Terrain can also affect the performance of an Rf network; neither path obstructions nor multipath interference are issues with this site location. 
Table 3. System gains and losses, $\mathrm{Grx}=0 \mathrm{dBd}$.

\begin{tabular}{|c|c|c|c|}
\hline Link Budget Parameter & Gains & Losses & Units \\
\hline Ptx & 30 & - & $\mathrm{dBm}$ \\
\hline Ltx & - & 3.04 & $\mathrm{~dB}$ \\
\hline Gtx & 6 & - & $\mathrm{dBd}$ \\
\hline Grx & 0 & - & $\mathrm{dBd}$ \\
\hline Lrx & - & 0.5635 & $\mathrm{~dB}$ \\
\hline Htx & 3.05 & - & Meters \\
\hline Hrx & 1.5 & - & Meters \\
\hline RxSensitivity & -110 & - & $\mathrm{dBm}$ \\
\hline
\end{tabular}

Table 4. System gains and losses, $\mathrm{GrX}=\mathbf{3} \mathrm{dBd}$.

\begin{tabular}{|c|c|c|c|}
\hline Link Budget Parameter & Gains & Losses & Units \\
\hline Ptx & 30 & - & $\mathrm{dBm}$ \\
\hline Ltx & - & 3.04 & $\mathrm{~dB}$ \\
\hline Gtx & 6 & - & $\mathrm{dBd}$ \\
\hline Grx & 3 & - & $\mathrm{dBd}$ \\
\hline Lrx & - & 0.5635 & $\mathrm{~dB}$ \\
\hline Htx & 3.05 & - & Meters \\
\hline Hrx & 1.5 & - & Meters \\
\hline RxSensitivity & -110 & - & $\mathrm{dBm}$ \\
\hline
\end{tabular}

Table 5. Fade Margin, Gtx $=6 \mathrm{dBd}, \mathrm{Grx}=0 \mathrm{dBd}$.

\begin{tabular}{|c|c|c|c|c|c|}
\hline Link Parameter & Units & Case 1 & Case 2 & Case 3 & Case 4 \\
\hline Distance from Tx & miles & 0.5 & 1 & 1.5 & 2 \\
\hline Prx & $\mathrm{dBm}$ & -66.3 & -78.4 & -85.4 & -90.4 \\
\hline Fade Margin & $\mathrm{db}$ & 43.7 & 31.6 & 24.6 & 19.6 \\
\hline
\end{tabular}

Table 6. Fade Margin, Gtx $=6 \mathrm{dBd}, \mathrm{Grx}=3 \mathrm{dBd}$.

\begin{tabular}{|c|c|c|c|c|c|}
\hline Link Parameter & Units & Case 1 & Case 2 & Case 3 & Case 4 \\
\hline Distance from Tx & miles & 0.5 & 1 & 1.5 & 2 \\
\hline Prx & $\mathrm{dBm}$ & -66.3 & -78.4 & -85.4 & -90.4 \\
\hline Fade Margin & $\mathrm{db}$ & 46.7 & 34.6 & 27.6 & 22.6 \\
\hline
\end{tabular}




\subsection{Remote system power budget}

Cost, physical size, and rating capacity of the solar panel and battery played a significant role when equipment was selected. Our approach was to choose a minimalistic remote solar-powered system design when selecting the amp-hour (Ahr) capacity of the battery and how much wattage the solar panel can produce. The location of the Moose Creek Dam (64.792522"N, 147.179987"W) proved to be a significant challenge. The available direct and scattered sunlight changes drastically throughout the year. Table 7 lists the approximate minimum amount of available sunlight hours during the event periods. Depending upon the time of the year, the power budget (Ahr/day) of the remote autonomous solar-powered equipment changes.

Three components of the autonomous system require $12 \mathrm{Vdc}$ power, the datalogger (CR300), piezometer (CS451), and the radio transceiver (MDS 900). The datalogger and piezometer sensor use very little power and are powered continuously, and collect data every 15 minutes; however, depending on the time of year, activation of the radio transceiver will change based on when the solar radiation is at the daily maximum. The radio is the largest consumer of power and has the capability of depleting the battery if there is not enough solar energy to recharge the battery.

During the spring and summer season (o1 April through 31 August), the radio transceiver will be powered "on" 24 hours a day. During this period, the base station collects measurements from the remote stations hourly to allow constant access to updated piezometer stage data during critical snowmelt periods. From 01 September through 30 September, it is assumed that this is a less critical time of the year (e.g., when a flood event most likely will not occur), the radio transceiver "on" time is scaled back to 15 minutes every hour. During the winter months, 01 October to $31 \mathrm{March}$, where solar radiation is at its lowest, the radio transceiver is set to power "on" once a day for 30 minutes, allowing the datalogger to run and collect data. Scaling back the radio transceiver "on" times reduces the power budget. When the radio is powered "on," all of the data collected between power cycles are collected by the base station and are posted to the database to be viewed on the website.

Table 7 lists the changing power budget of the system and the minimum source current of the solar panel required to maintain the battery voltage potential. After calculating the power budget and minimum solar panel source 
current to maintain a charge, a $12 \mathrm{Vdc}, 12 \mathrm{Ahr}$ lead acid battery and 20-watt solar panel with a maximum source current of 1.12 Amps was chosen.

Table 7. Schedule for activating the radio transceiver to account for change in the amount of available sunlight.

\begin{tabular}{|l|l|c|c|c|c|}
\hline \multicolumn{1}{|c|}{ Period } & $\begin{array}{c}\text { MDS on } \\
\text { Times }\end{array}$ & $\begin{array}{c}\text { Average } \\
\text { Current Drain } \\
(\mathrm{mA})\end{array}$ & $\begin{array}{c}\text { Daily Current } \\
\text { Drain } \\
\text { (Ahr/day) }\end{array}$ & $\begin{array}{c}\text { Minimum Solar } \\
\text { Panel Source } \\
\text { Current (amps) }\end{array}$ & $\begin{array}{c}\text { Minimum } \\
\text { Available } \\
\text { Sunlight (hrs.) }\end{array}$ \\
\hline 1 Apr - 31 Aug & Continuous & 149.74 & 3.594 & 0.331 & 13 \\
\hline 1 Sept - 30 Sept & $15 \mathrm{~min} / \mathrm{hr}$. & 39.25 & 0.984 & 0.107 & 11 \\
\hline 1 Oct - 31 Mar & $30 \mathrm{~min} /$ day & 7.76 & 0.186 & 0.0558 & 4 \\
\hline
\end{tabular}




\section{Data Delivery}

\subsection{Network environment}

A high-speed network connection exists within the Control Works of the Moose Creek Dam, which is connected to the U.S. Army Corps of Engineers (USACE) Enterprise Information Technology (IT) environment. In 2008, USACE standardized computing across USACE, which placed many limitations on the network. In response to this change, the U.S. Army Engineer and Development Center (ERDC) created a non-production IT computing network infrastructure known as the Research and Development Environment (RDE). The RDE network offers the same assurance oversight and governance as the U.S. Army Corps of Engineers-Information Technology (ACE-IT) network, by providing a computer services environment that can flexibly evaluate and leverage computing technologies necessary to provide a solution to many different problems (ERDCpedia 2016).

The communication network at the Control Works can be separated into three pieces, each of which depends on the others to function correctly (Figure 15). The first piece is the necessary connection to the ACE-IT network, which provides the essential network connection that meets the USACE requirements. The second piece is the RDE network; a link to the $\mathrm{RDE}$ servers is created by employing a hardware device called a virtual private network (VPN) concentrator. The concentrator is connected to the ACE-IT switch and opens a virtual encrypted tunnel to the ERDC RDE servers. The third piece is the demilitarized zone (DMZ), which is the area where the public server resides, for access by people who might otherwise not be trusted. Permissions must be granted by network administrators from both RDE and ACE-IT networks. 
Figure 15. Network configuration.

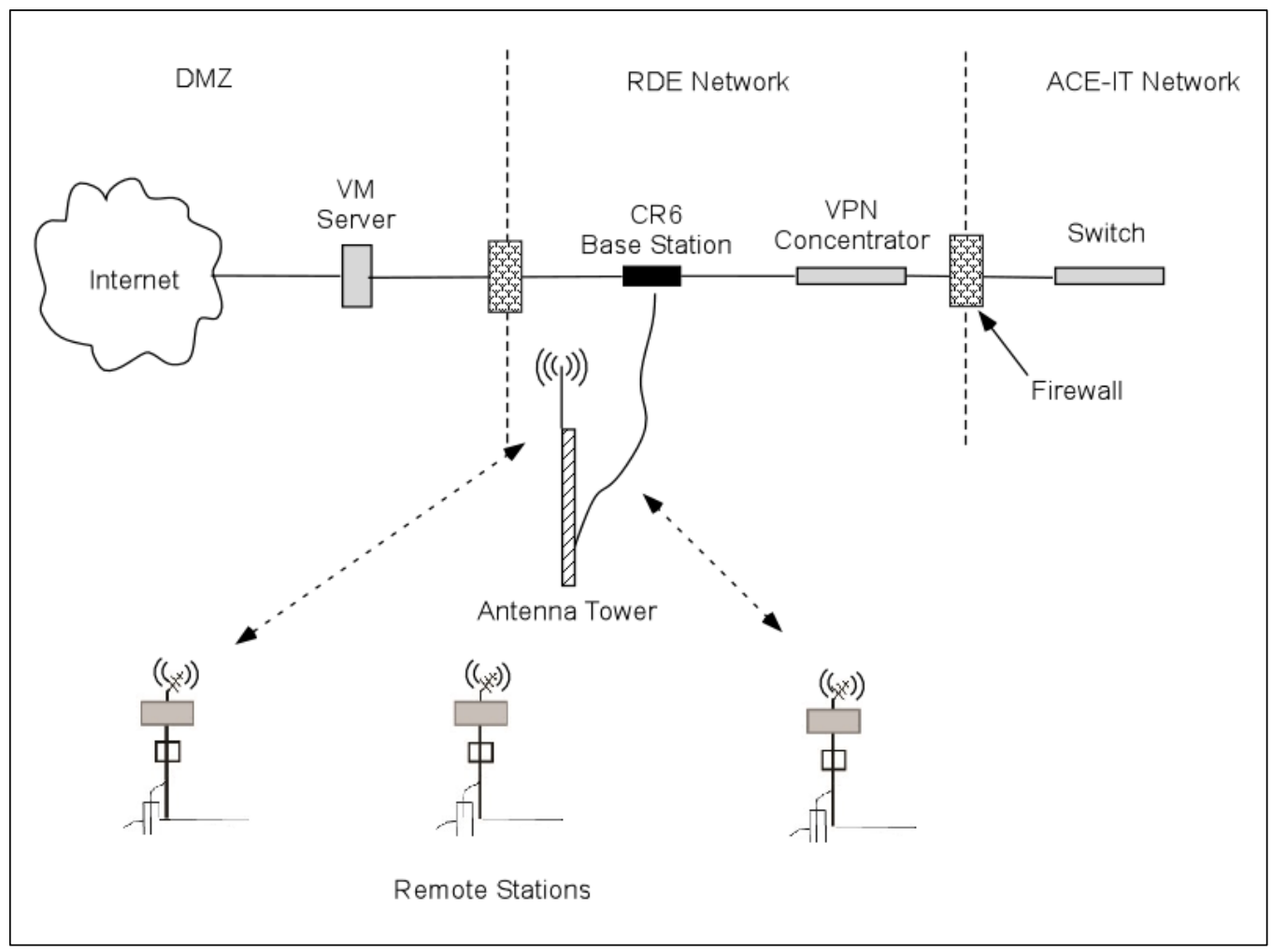

\subsection{Database software}

Selecting a method of presenting the data via a web interface involved the creation of a set of criteria that the candidate database software must satisfy. It was important for the data to be accessible to interested parties in addition to the U.S. Army Corps of Engineers, such as the National Oceanic and Atmospheric Administration, National Weather Service, Bureau of Land Management, and others. The software also needed to have the capability to generate alarms based on a set of conditions, to provide a means of storing data for long term analysis, and to interface directly with the dataloggers to avoid the need for the database to interface with many different applications.

Canary Systems Inc. (CSI), located in New London, NH, is a systems integration, peripheral hardware manufacturer and software company that works in many fields, including Dam Monitoring. CSI has developed an integrated management software, MultiLogger Suite (MLSuite ${ }^{\circledR}$ ), which offers an integrated platform of three components that are capable of programming and retrieving data from the Campbell Scientific dataloggers 
and hosting the data in a structured query language (SQL) database through a web interface.

Figure 16 shows the relationship between the different components of the MLSuite ${ }^{\circledR}$ package. Canary Systems was contracted to provide training and support services to assist with the establishing the data-logging network. The system is not an intuitive system to learn and the training was necessary. If a user is familiar with the Campbell Scientific dataloggers and their programming software, the learning curve is not quite as steep.

MLSuite ${ }^{\circledR}$ resides on the Virtual Machine (VM) Server and can be accessed remotely from the RDE network. Four components, MLGateway ${ }^{\circledR}$, MLServer ${ }^{\circledR}$, MLWeb $^{\circledR}$, and SQL Server are essentially tools that run in the background and allow the different pieces to interact with each other. Multilogger ${ }^{\circledR}$ handles the communication and programming of the dataloggers. MLWeb ${ }^{\circledR}$ Client is the web interface component that interacts with the SQL Server to view and display the collected data.

Figure 16. Network diagram for Canary Systems MLSuite ${ }^{\circledR}$ software package.

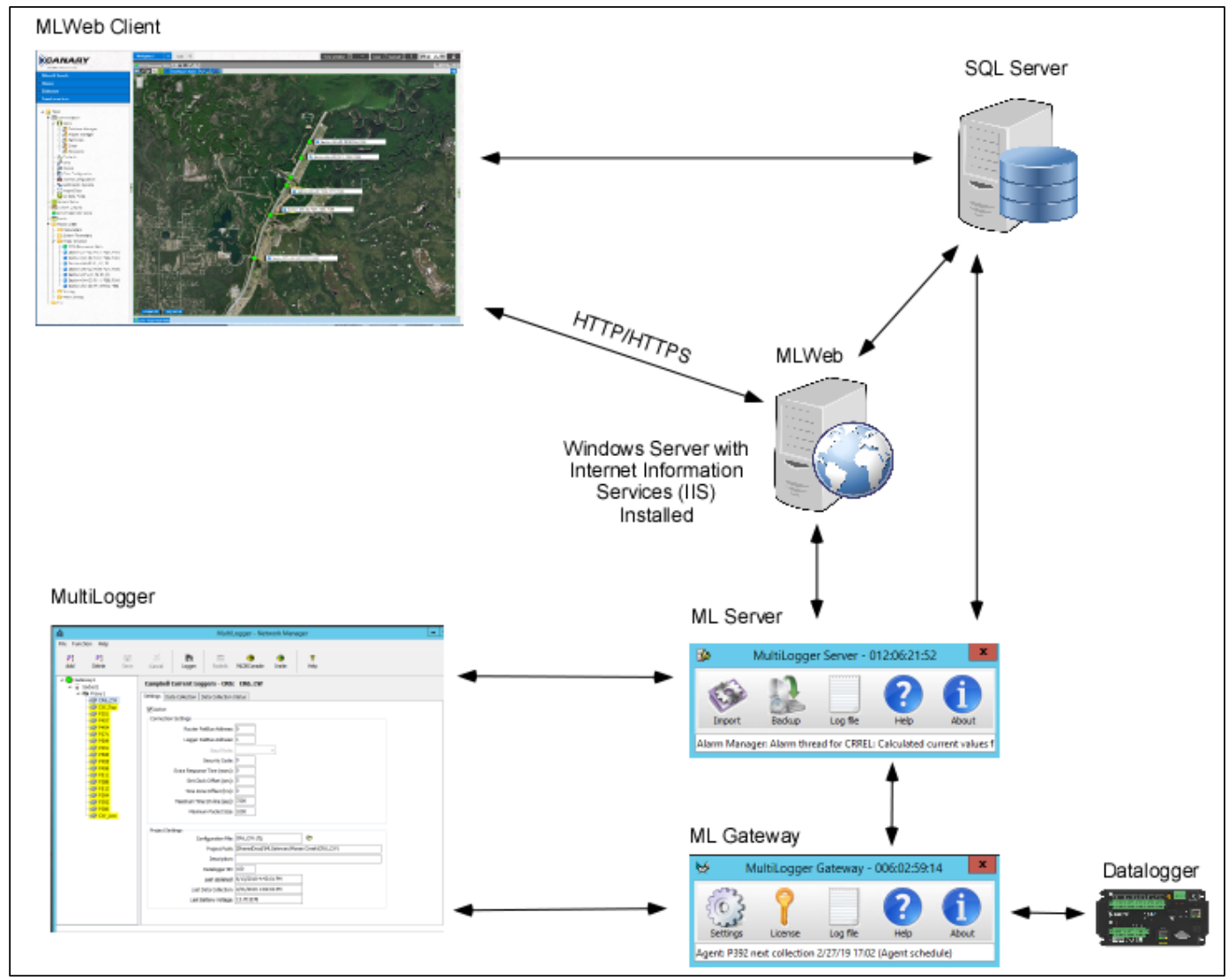




\section{Installation and Lessons Learned}

\subsection{Summer installation}

Installation of the sensor network took place from May 30 through June 15, 2018. The installation consisted of 15 sites along the dam embankment and six within the Control Works structure. The installations outside of the Control Works were nearly all the same except for the 17 fence poles that needed to be installed along the embankment. That proved to be a challenge because of the gravel base. A drilling rig had to be brought in to predrill holes to install the fence poles. After installing the fence pole, the datalogger equipment enclosure, solar panel, and antenna were mounted (Figure 17a). The solar panel was orientated due south with a desired tilt of latitude plus 15 degrees. The intent was to focus on the sun declination during the winter months. Each piezometer well had to be sounded to obtain the true depth. With that depth reading, the pressure transducer was installed $1 \mathrm{ft}$ off the bottom.

One challenge with the installation of the data-logging equipment proved to be with the piezometers located within the structure of the Control Works. P3 and P6 are located on top of the Control Works, flush with the concrete surface. A large crane parked on top of the Control Works is used during bailing operations to remove debris that builds up when the flood gates are closed. To protect the data-logging equipment, the box and solar panel are placed at a considerable distance from the area where bailing would take place, and the sensor cables are placed within an expansion joint that runs along the length of the structure (Figure 18a and b) and that is covered with a rubber gasket compound for protection. Piezometers P1 and $\mathrm{P} 4$ are located just above the river at the base of the Control Works. The equipment for these two is mounted on top of the Control Works (Figure 18c). A fence post was attached to the existing railing to provide a mounting for the enclosure, solar panel, and antenna. P2 and $\mathrm{P}_{5}$ are located within the Control Works (Figure 18e and f) where the cables were run to the base station that is located within the small room that houses the network equipment (Figure 18d). The two piezometers within the control work were connected to the base station. 
Figure 17. View of a cross-section with three piezometers (a), with a station at the crest of the embankment (b), the toe of the embankment (c), and at the toe of the stability berm (d).

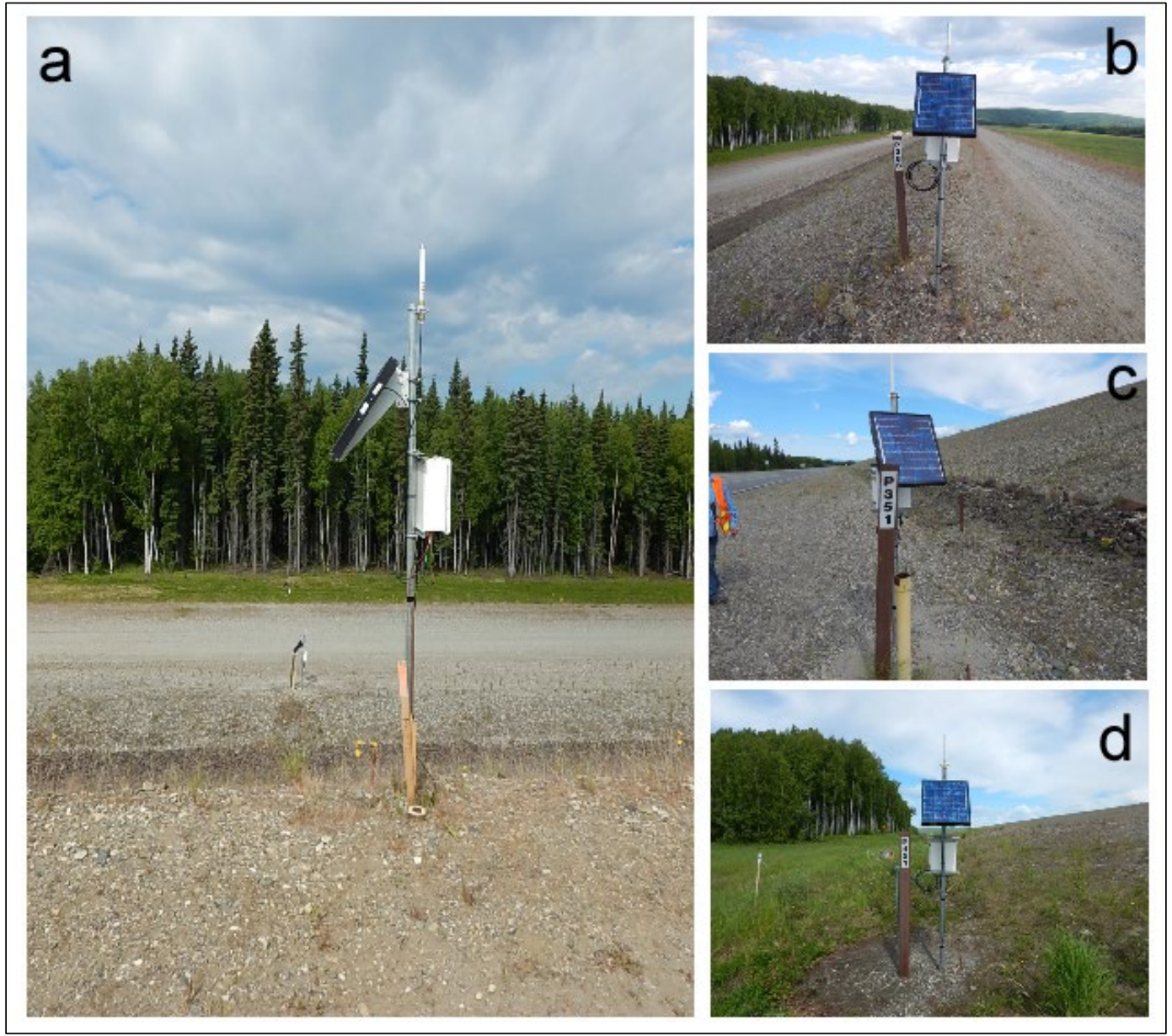


Figure 18. Six piezometers are located within the Control Works structure. For the top piezometers, the sensor cable was run along the expansion joint (a) to a location away from bailing operations ( $b$ and $c$ ). The base station is located within the Control Works (d), and two piezometers are in the gallery of the Control Works (e and $f$ ).

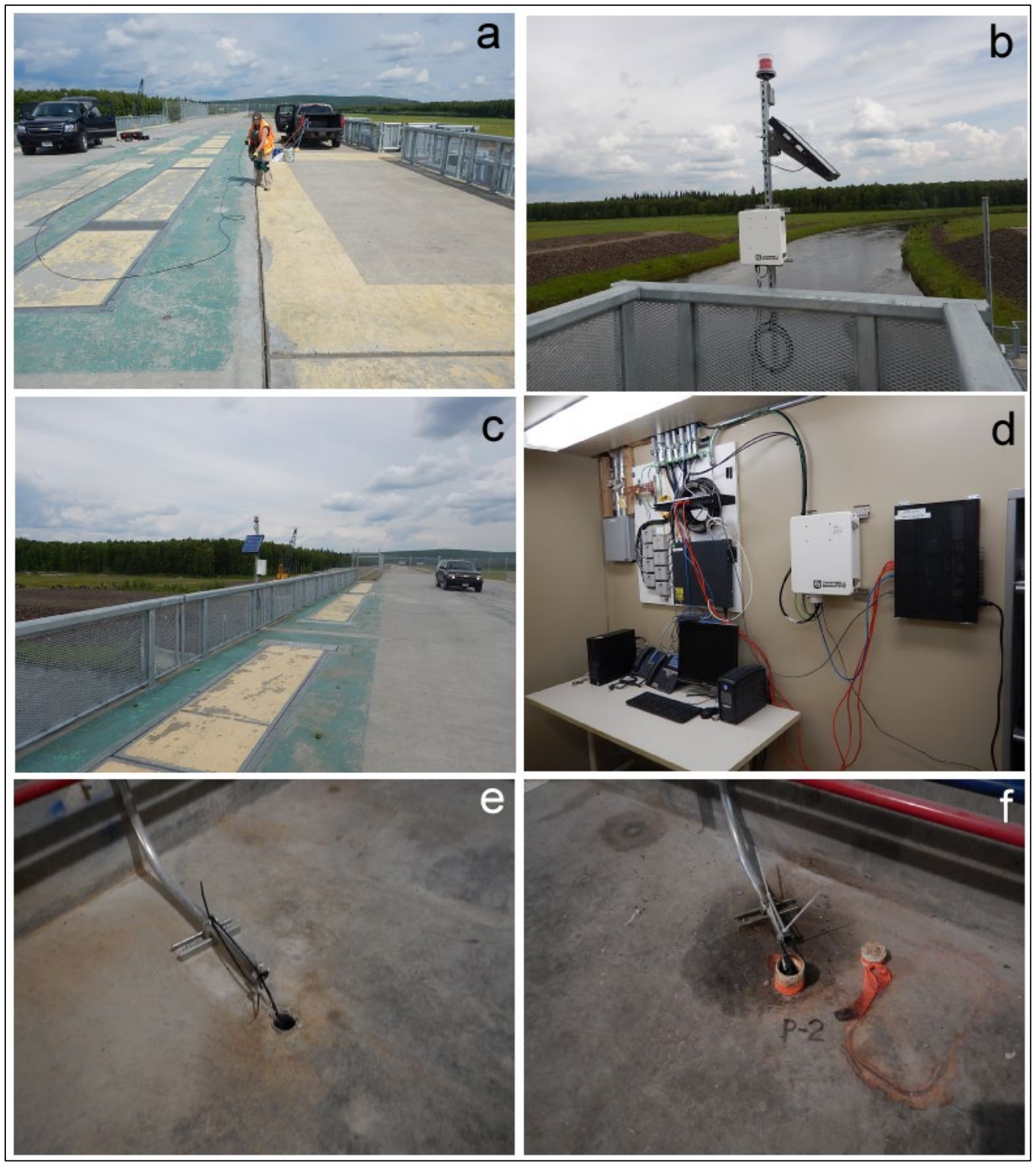




\subsection{MLWeb interface}

MLWeb $®$ is the software platform used to render a project database for web browser viewing and interaction. It is designed to run on Microsoft $\AA$ Internet Information Services and can work on a variety of Windows server platforms such as Microsoft Windows Server ${ }^{\circledR} 2012$ (Canary Systems 2018). Although MLWeb ${ }^{\circledR}$ includes too many features to describe in detail, a few features have been selected that highlight key areas of interest. Figure 19 shows the main workspace where customized views are created. The center of the window is the workspace where different types of panels can be displayed, e.g., image windows, charts, reports. On the left is the tree view that is used to navigate among the different configurations and function. Links represented by the green icons are used to allow easy navigation to different project views, and description boxes are shown for each link.

Figure 20 gives a second view showing the cross-section of three piezometers located at Station $360+00$. Stationing is used as a process to define locations along the dam, e.g., the dam begins at Station $55^{+00}(5,500 \mathrm{ft})$; Station $360+00$ is $30,500 \mathrm{ft}$ from the beginning of the dam. Here the description box displays the current reading of pressure and water temperature for the associated piezometer. Color indicators show the system status: green indicates that the data is up to date and red shows that the site is in error state. Additional outputs can be added to the description box, e.g., links to associated documents and associated outputs such as elevation and temperature plots (Figure 21). 


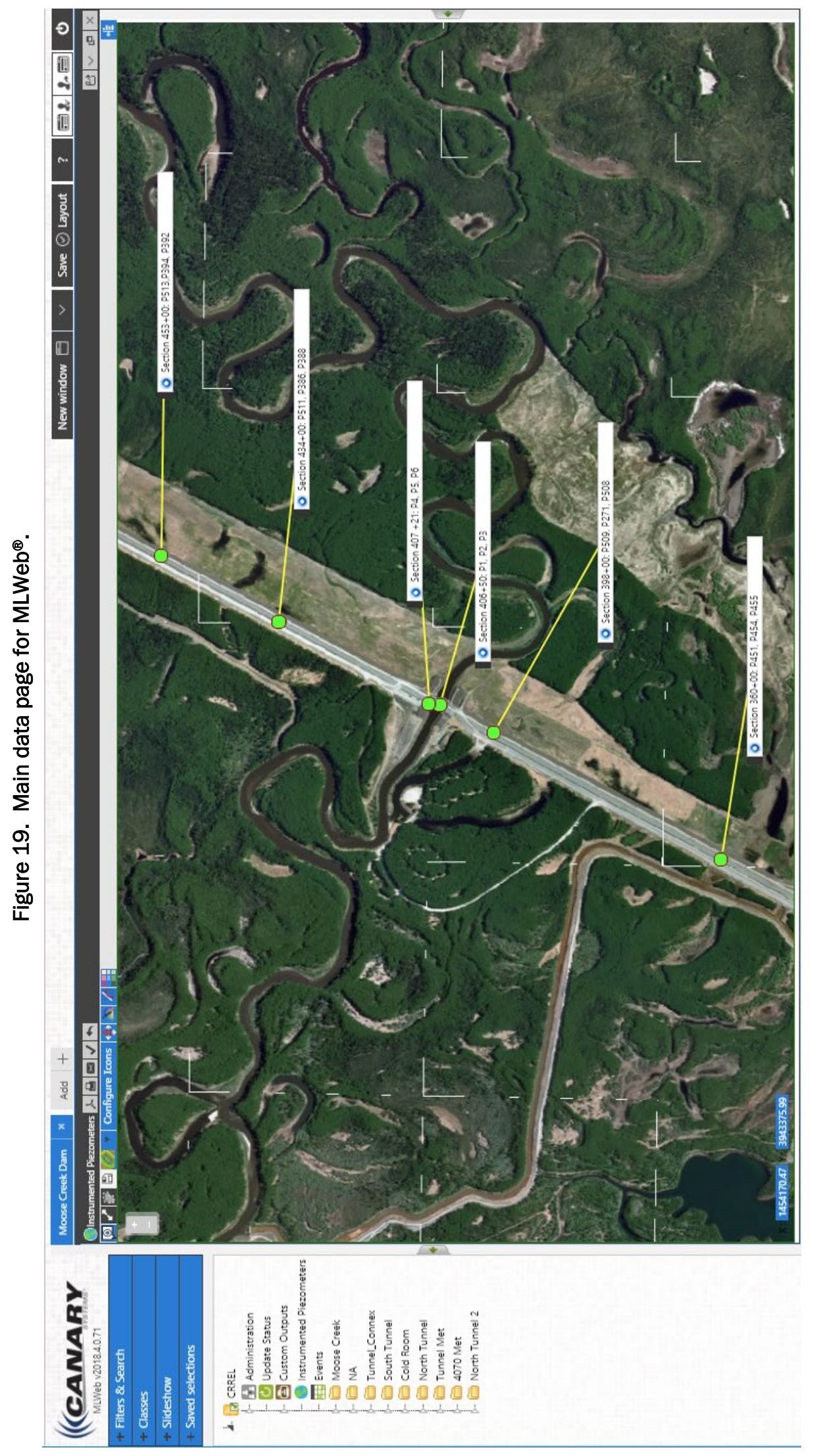




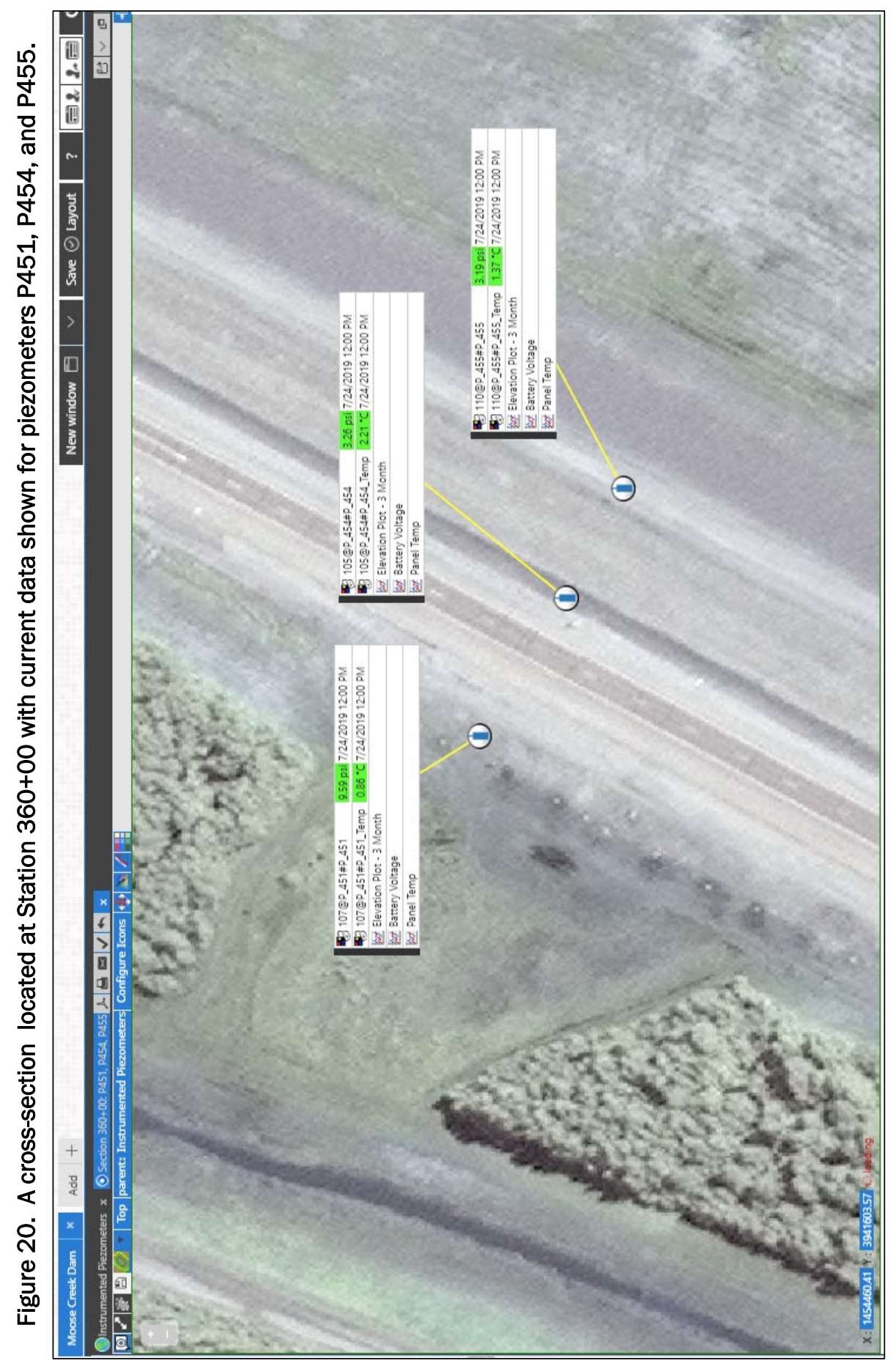




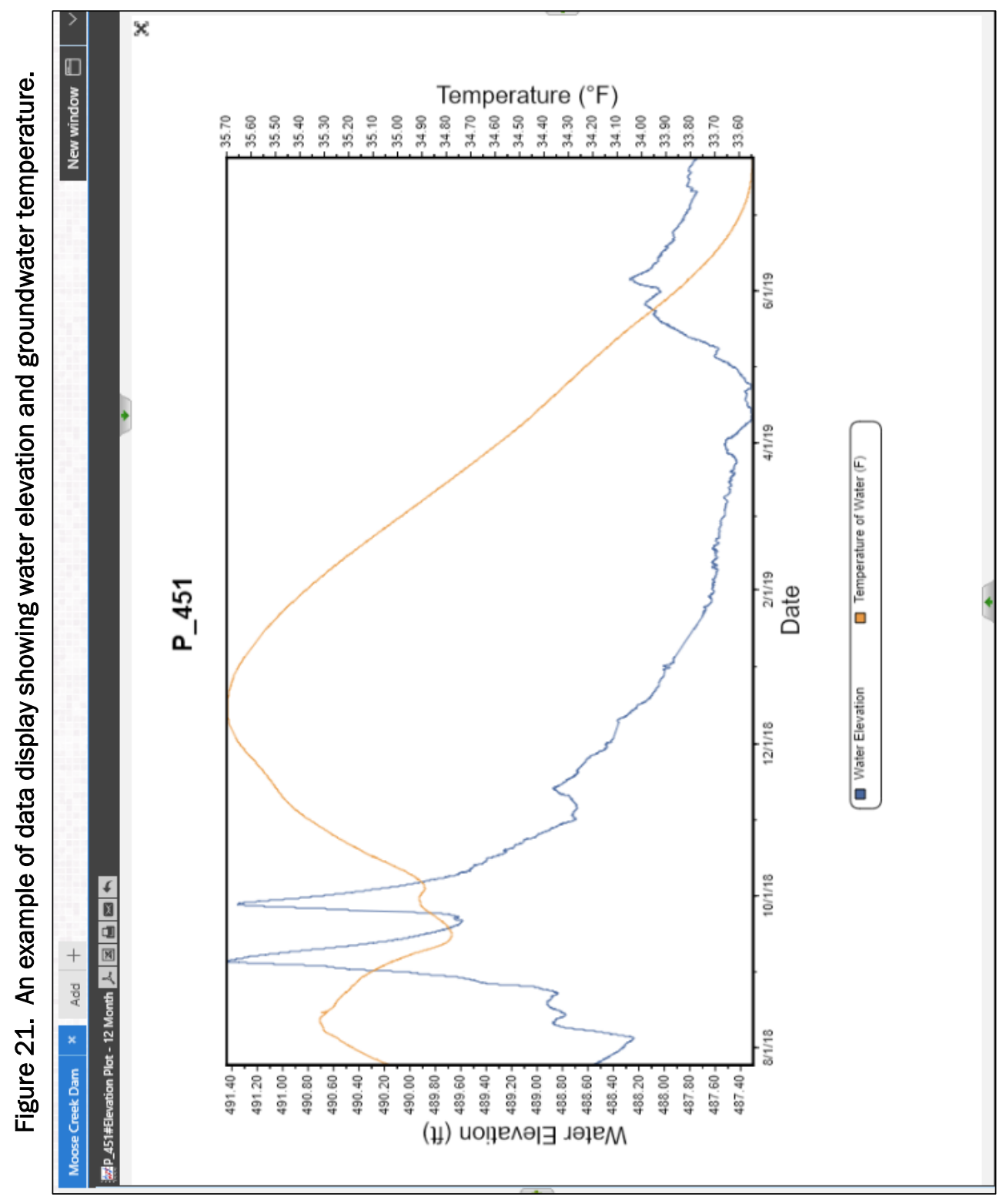




\subsection{Piezometer data for cross-sections for the embankment}

Once the sensor network was successfully installed, it began to collect data on June 13, 2018. Figures 22 through 26 show the resulting water elevations as measured at the piezometers for each cross-section through the summer of 2018. Each plot also shows the river stage gage data from the nearby U.S. Geological Survey (USGS) monitoring station, located on the Chena River below the Control Works (although the monitoring station stops recording river data when the river freezes). These figures also show that the data taken from each piezometer are similar to the river stage gage data. The peaks in the USGS data indicate the rise of the river due to rain events and each piezometer sees the same response.

September 2018 was a particularly wet month. Groundwater peaks occurred twice, the first on September 5 and the second on September 27, when the dam operators were considering closing the gates at the Control Works. The ground elevation for the piezometer located at the toe of the stability berm was used to provide a reference line to help determine the actual depth of the groundwater. The groundwater at Station 360+0o was approximately $0.66 \mathrm{ft}(0.20 \mathrm{~m})$ below the ground surface. This was the shallowest seen along all the cross-sections of the instrumented piezometers along the embankment. Also, note that there are small differences in the water elevations at each piezometer. (It was initially thought that there were errors within the survey data.) Ground elevations and sensor positions have been verified and it is assumed that these values are correct. 


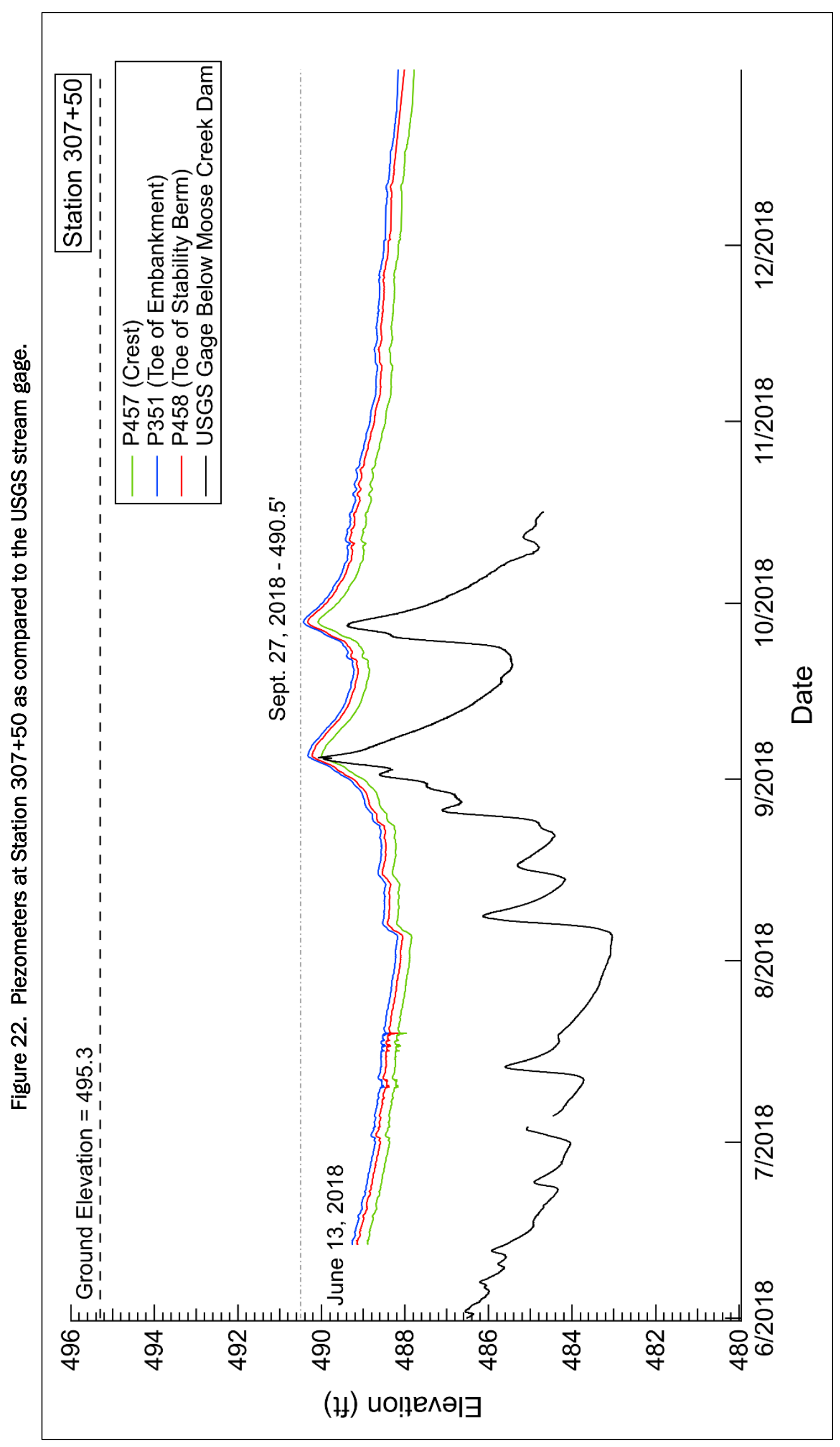




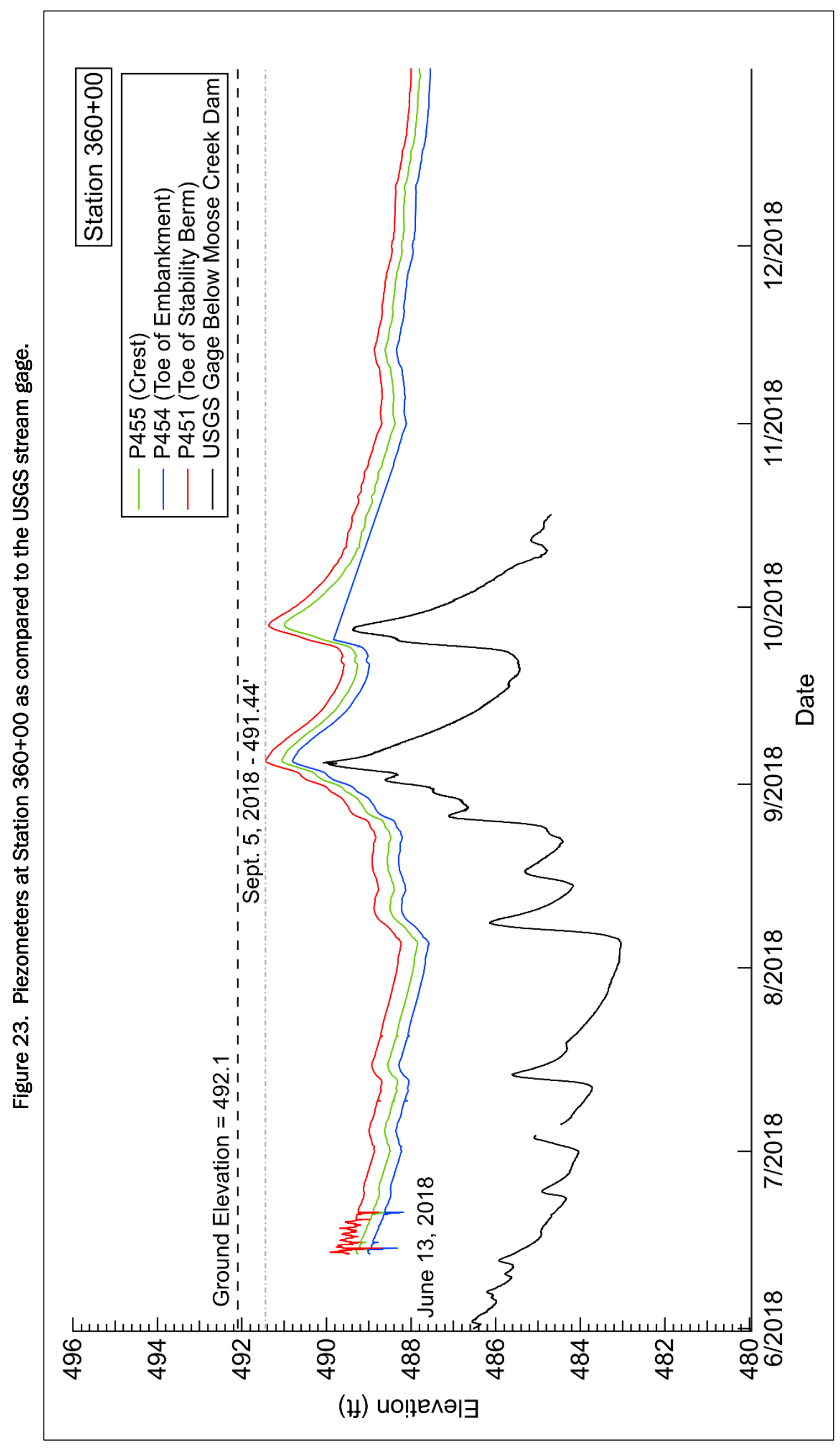




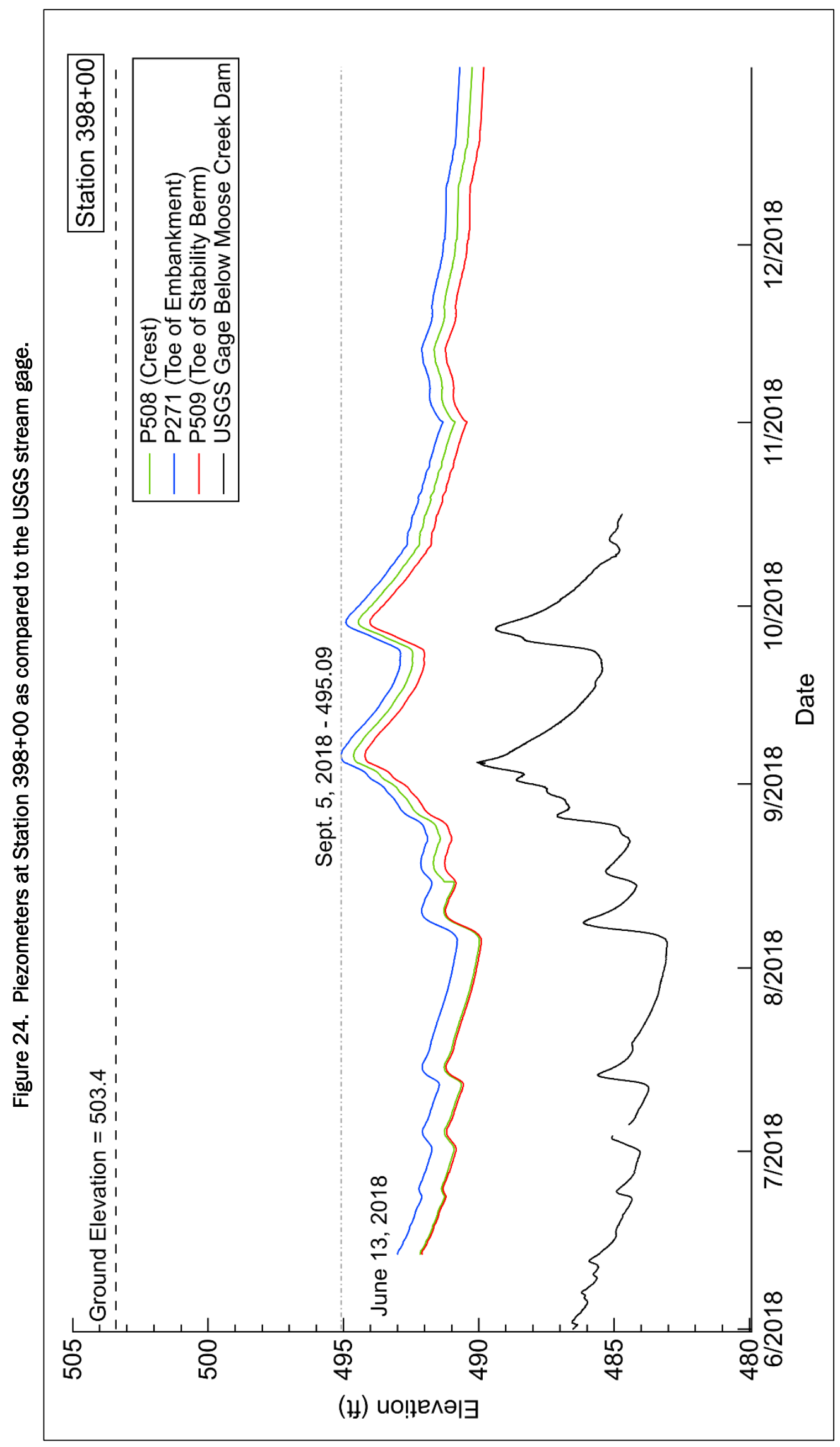




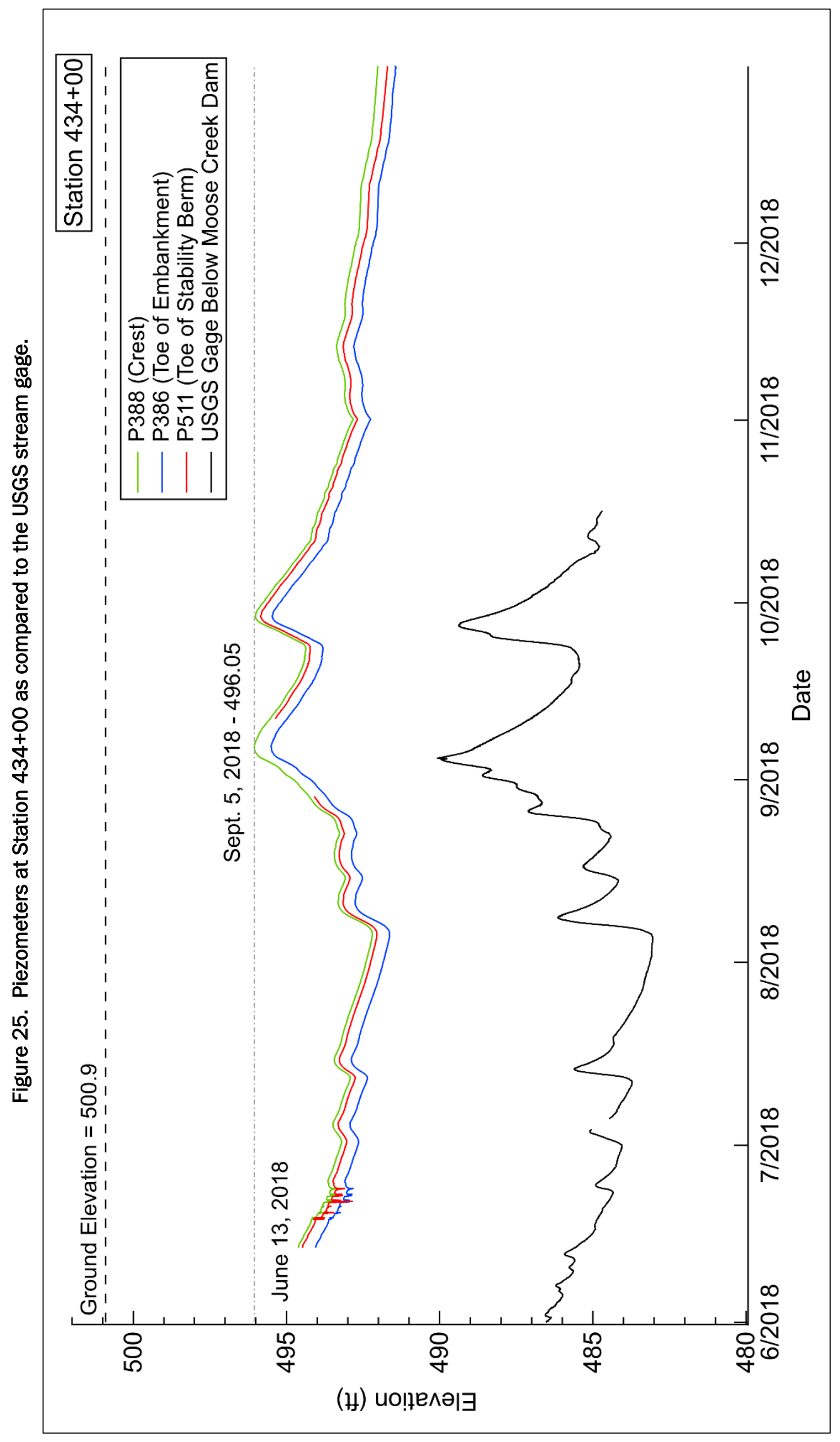




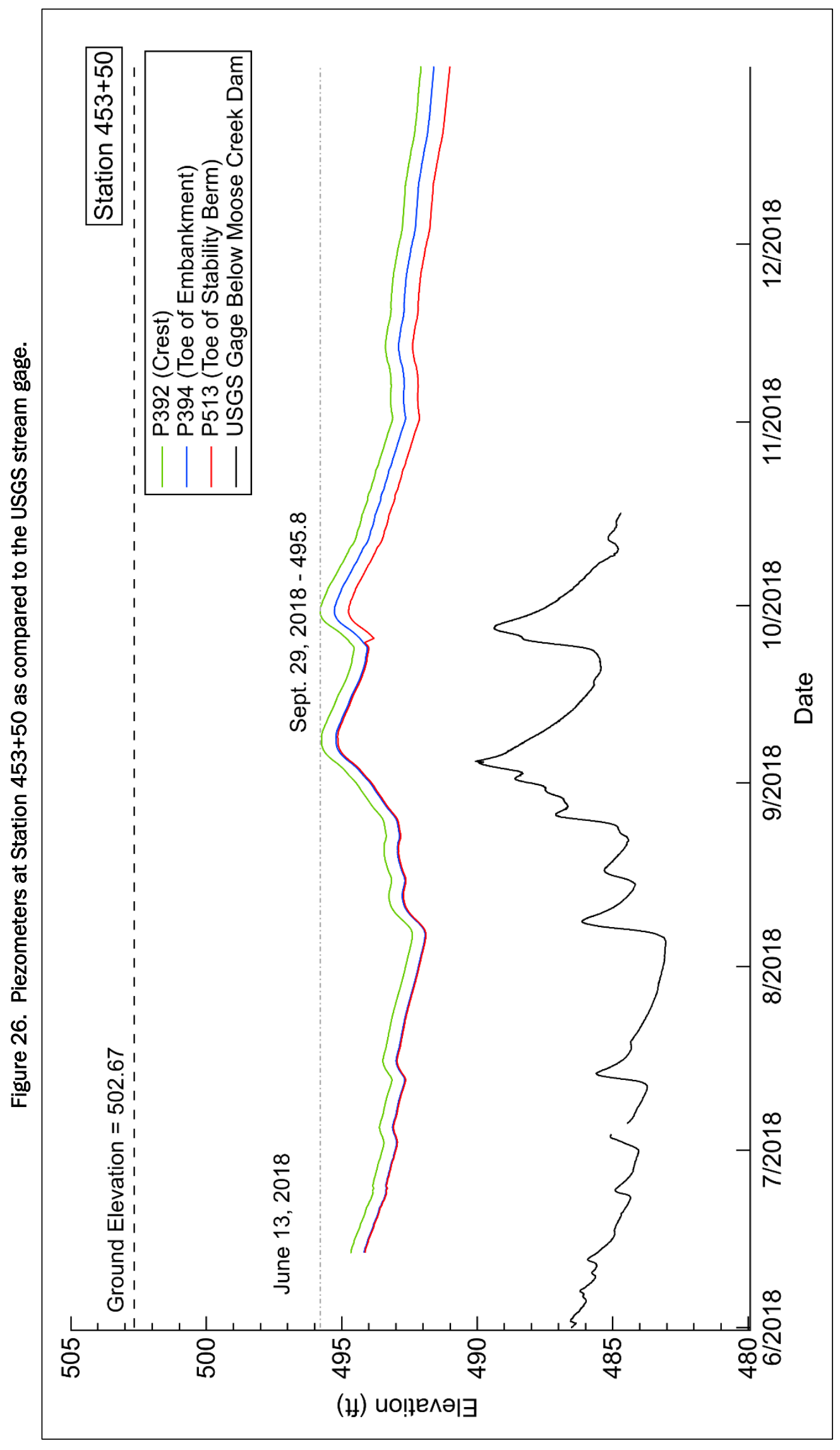




\subsection{Piezometers within the Control Works}

Of all the piezometers, those within the Control Works were the most challenging to install and monitor. There are two cross-sections at the Control Works, Station $406+55$ and Station $407+71$, where piezometers are located at the top, inside the gallery, and within the downstream piers (Figure 3). The water elevations are plotted in the same manner as those on the embankment (Figures 27 and 28). The water elevation matches quite well to that of the USGS stage gage, which, again, is expected. The delay is minimal because the piezometers are essentially located within the Chena River.

The data charted in Figure 28 illustrate one of the issues with the piezometers located at the top of the Control Works. The sensor at P6 experiences data spikes, which is assumed to be caused by rain infiltration through the PVC casing. On August 16, 2018, the dam operators attempted to clear out the debris from the piezometers. This evidently had an effect since the water elevation for P6 dropped to match more closely to that of $\mathrm{P}_{5}$.

An error that occurred during the data transfer from the data files to the SQL database caused a loss of data for $\mathrm{P} 1$ and $\mathrm{P} 4$. This error was discovered after updating the software and its source has not been determined. For example, there are times when the MLServer service needs to be manually restarted, using the Task Manager on the server; the software developer is aware of this and is working to address this issue. This issue may be contributing to the data transfer error.

It was assumed that the depth of the piezometers would protect the sensors from freezing. However, this was not the case for the sensors within the Control Works. The piezometer P2 froze up at some time during the month of December such that it gave a false reading to the sensor (Figure 29). Steps may need to be taken for future work to remove these sensors, or to otherwise protect them from the cold. After each summer, these sensors will need to be pulled out of the piezometers or the cables will need to be extended to get them deeper into the water table. Removal will be troublesome for $\mathrm{P} 3$ and $\mathrm{P} 6$ as the cables are encased in the rubber compound in the expansion joint; however, these two piezometers appear not to have been frozen and may not need to be relocated. 


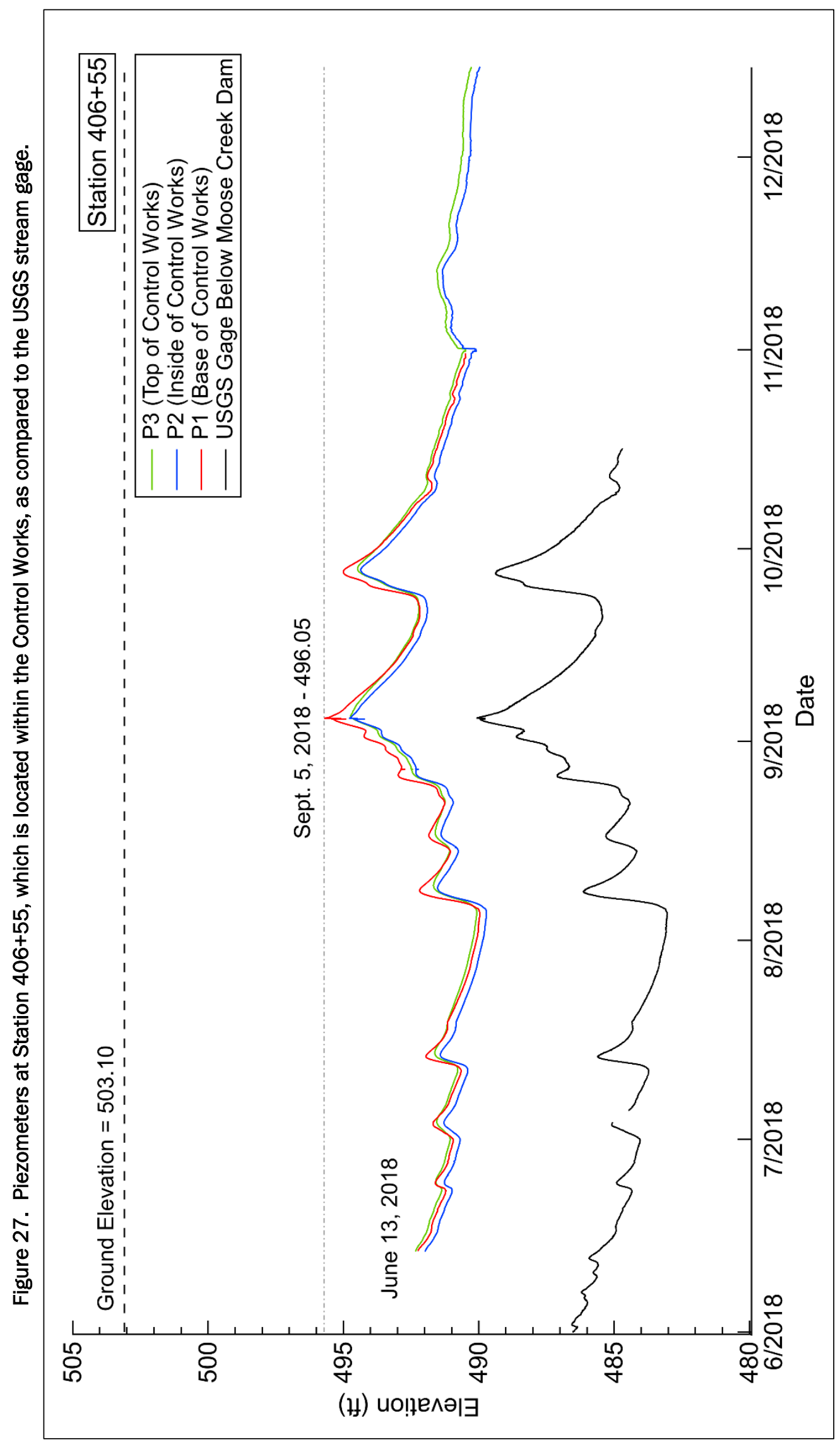




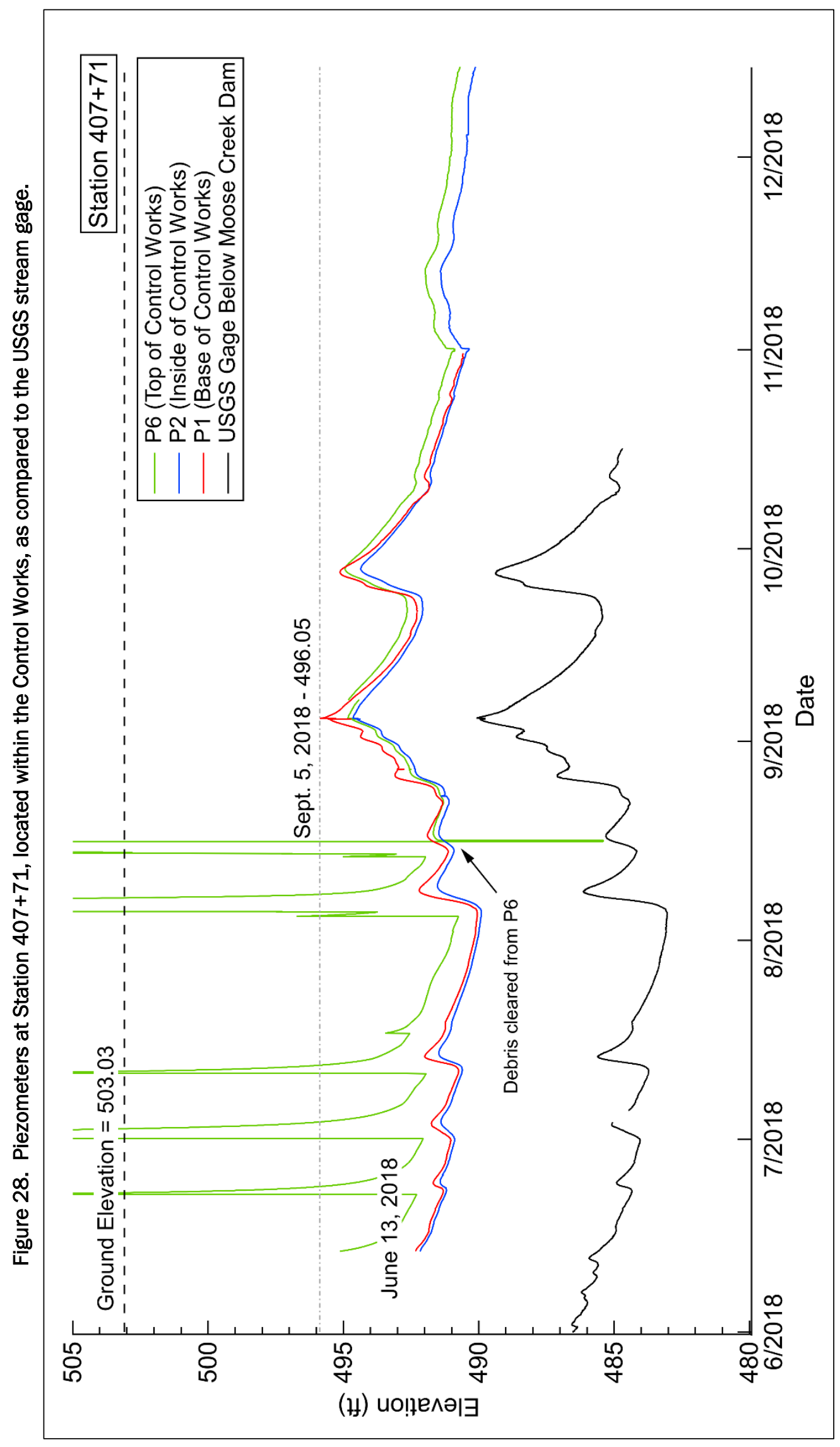




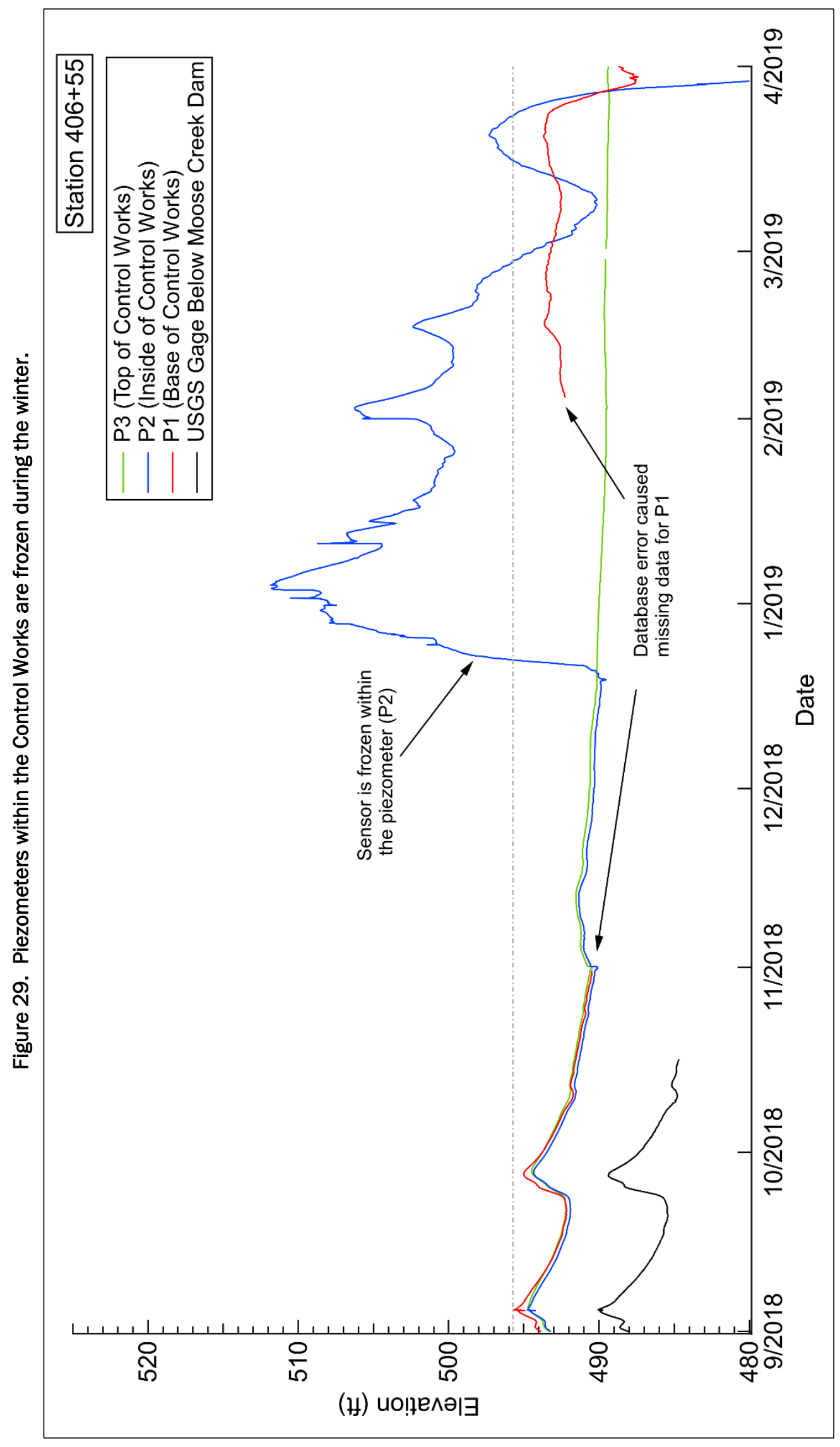




\subsection{Remote system power performance}

Overall, the power budget scheme performed well. During event periods one and two (Table 7), the battery and solar panel combination provided the required amp-hour capacity to power the system. During event period three, some of the systems began to shut down. A few factors contributed to the early shutdowns of the remote systems. In November 2018, Canary Systems pushed an update to their MultiLogger Software that contained a programming error that created data collection issues. The troubleshooting efforts to determine the error required that many of the remote systems be powered continuously. Powering the remote systems continuously at this time of year set the stage for early failure. In late January 2019, all issues with MultiLogger were resolved, but, by that time of the year, there was not enough available sunlight for the batteries to recover. Figures 30 and 31 show the battery performance of two remote sites. Piezometer P458 (Figure 30) was powered continuously for a period to assist with debugging the data collection issues while P386 (Figure 31) followed the power budget scheme listed in Table 7. The performance of system $\mathrm{P}_{3} 86$ indicates that, by increasing the wattage of the solar panel and adjusting the powering scheme, a continuous battery operation for all remote sites can be achieved.

Figure 30. Piezometer P458 battery performance.

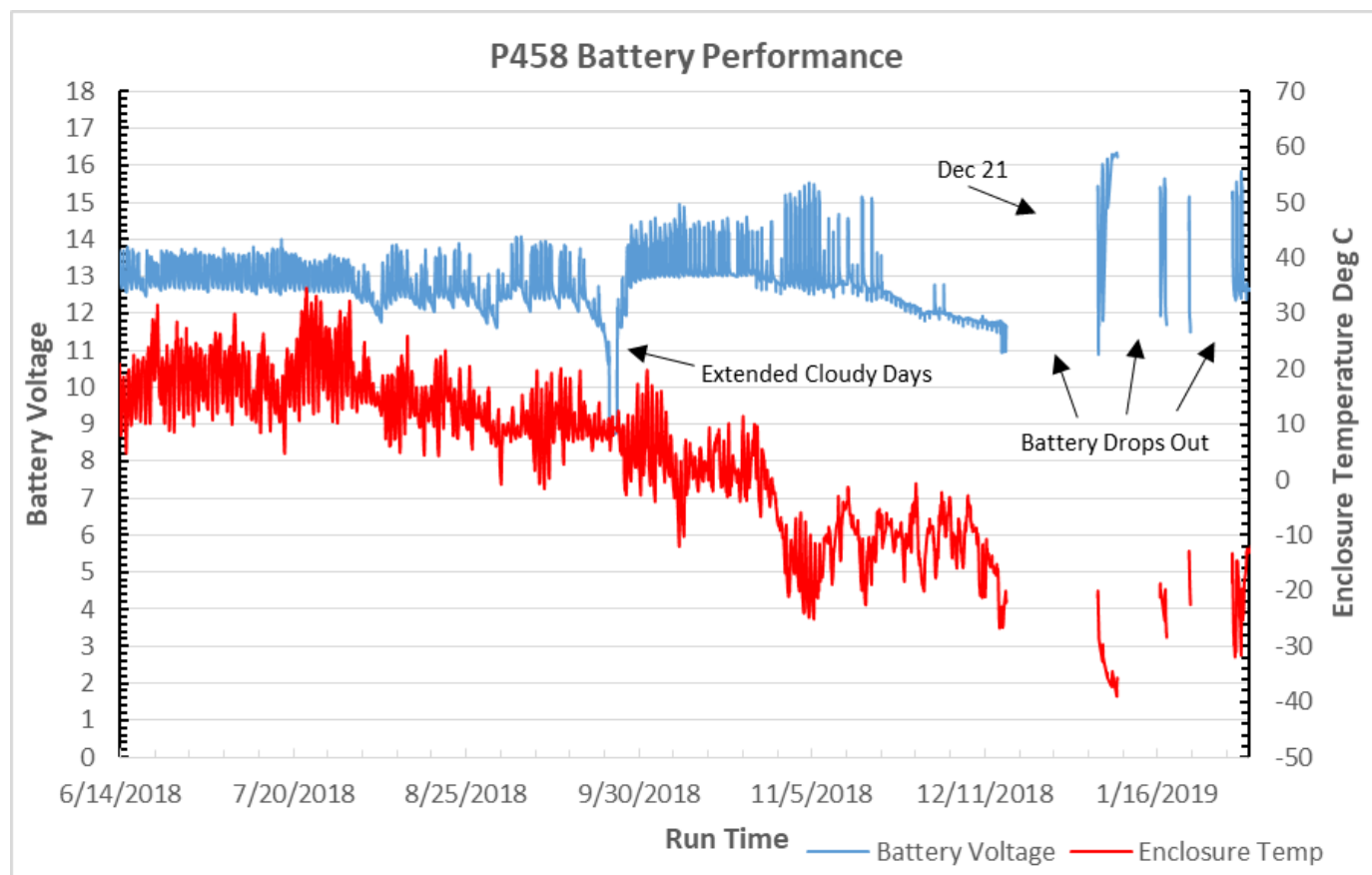


Figure 31. Piezometer P386 battery performance.

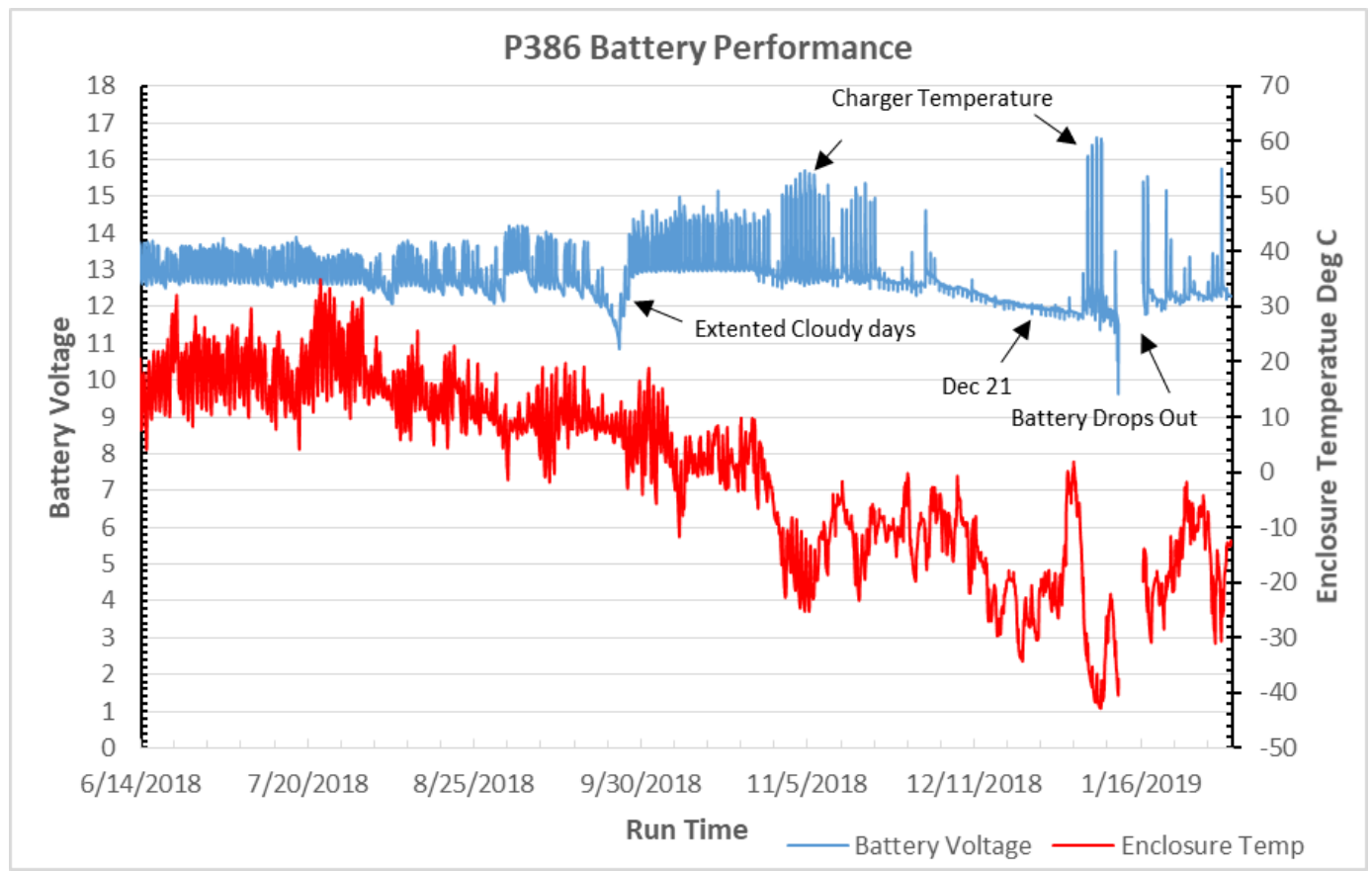

\subsection{Adjustments for power budget}

After monitoring the performance of the power budget scheme for the first season of operation, it was decided to make a few changes to the power system and to adjust the MDS radio activation times. Throughout the summer of 2018, the batteries dropped below 12 volts several times, which caused some concern as to whether our power budget calculations were adequate. It has since been determined that the amount of solar radiation that the Fairbanks and North Pole area received was at an all-time low. Figure 32 illustrates the yearly solar radiation for a 10-year period; the trend line for the 10-years indicates that the amount of solar radiation will continue to decline. To take this into account, the solar panel wattage will be increased from 20 watts to 30 watts. This increase in wattage will allow an increase in battery charging capacity during the months of low sunlight availability. 
Figure 32. Yearly solar radiation for Fairbanks, AK (2009 - 2018).

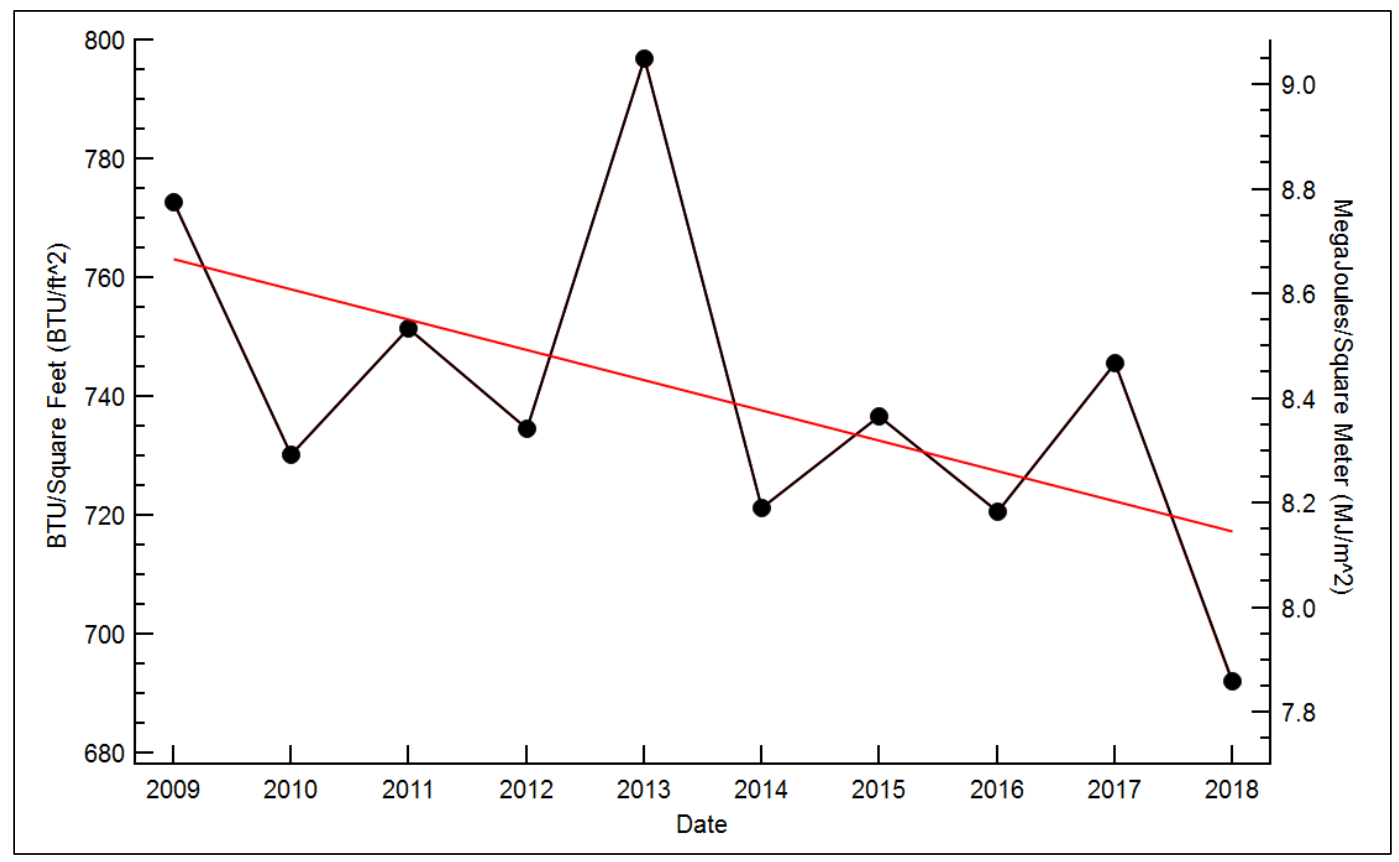

For the winter months, the MDS radio "on" time schedule will be adjusted to ensure uninterrupted performance of the data collection system. Table 8 lists the new MDS radio "on" time schedule. The most dramatic change is event three. During the period 1 October through 15 February, the months with the least amount of available sunlight, the MDS radio will be turned off. No data will be collected or posted by the Canary System software during that period. The datalogger will still collect Piezometer data and store it in onboard memory. Finally, the 12-volt 12-Ahr battery will be swapped for a 12-volt $10 \mathrm{Ahr}$ lithium battery, which is more tolerant of cold temperatures and which will provide more battery capacity during those times.

Table 8. Recommended settings for collecting data based on time of year.

\begin{tabular}{|c|c|c|c|c|c|c|}
\hline Event & Period & $\begin{array}{c}\text { MDS on } \\
\text { Times }\end{array}$ & $\begin{array}{c}\text { Average } \\
\text { Current Drain } \\
(\mathrm{mA})\end{array}$ & $\begin{array}{c}\text { Daily Current } \\
\text { Drain (hr./day) }\end{array}$ & $\begin{array}{c}\text { Minimum Solar Panel } \\
\text { Source Current(amps) }\end{array}$ & $\begin{array}{c}\text { Minimum } \\
\text { Available } \\
\text { Sunlight (hrs.) }\end{array}$ \\
\hline 1 & 1 Apr-31 Aug & Continuous & 149.74 & 3.594 & 0.331 & 13 \\
\hline 2 & 1 Sept-30 Sept & $15 \mathrm{~min} / \mathrm{hr}$. & 39.25 & 0.984 & 0.107 & 11 \\
\hline 3 & 1 Oct-15 Feb & Off & 6.48 & 0.155 & 0.047 & 4 \\
\hline 4 & $16 \mathrm{Feb}-31 \mathrm{Mar}$ & $30 \mathrm{~min} /$ day & 7.76 & 0.186 & 0.028 & 8 \\
\hline
\end{tabular}




\section{Conclusion}

The most significant flood event at the Moose Creek Dam occurred in 1992, where the dam impounded water to an elevation of $512.7 \mathrm{ft}$ (NGS 2018), which is approximately $19 \%$ of its capacity (USACE 2010). During this flooding event, only a few water level measurements were taken at the piezometers, and records were not kept. Regular water level measurement at the piezometers did not occur until the summer of 2014. During that time, two relatively minor flooding events occurred creating areas of distress along the stability berm. As a result, nearly 1000 small pin size sand boils became evident downstream of the stability berm. The development of these boils indicate that there could be the start of backward erosion and piping that could cause failure of the dam. Prior to the automation of these 21 piezometers, manual measurements were taken, which provide a single data point at the time of collection. Data are now being collected every 15 minutes starting with the June 2018 installation. This data is being displayed via a web-based interface that provides real-time situational awareness at five cross-sections along the embankment of the dam. As additional piezometers are instrumented, the added information will enable the Alaska District to develop safety responses to potential dangers.

The data world is shifting; current access to high-speed networks and advanced software has made data telemetry one of the best and quickest ways to save time and money when gaining situational awareness. The ability to use the RDE computer services environment has created the foundation to host and display real-time data through a web-based application, which in turn enables a much broader user base to build upon this system. The approach that we have taken to select a data-logging system, which involved considering the distances between the instrument locations for antenna selection, calculating the power consumption of each component, and determining the frequency of the data to be collected, has increased our chances of success by allowing us to start with a system that would meet the need for reliable data collection. This base configuration of the data systems has allowed us to fully explore and determine the power requirements and improvements that the system requires, and that will ensure the system's long term viability. The resulting access to real-time data yields rapid insight into current conditions, while preserving the data for future analysis. 


\section{Bibliography}

\section{Cited works}

Campbell Scientific, Inc. 2016 "CS451/CS456 Submersible Pressure Transducer." Product Manual. Logan, Utah: Campbell Scientific, Inc., 8. https://s.campbellsci.com/documents/us/manuals/cs451-cs456.pdf.

. 2018a. "The Link Budget and Fade Margin." Application Note. Logan, Utah: Campbell Scientific, Inc., 9. https://s.campbellsci.com/documents/us/technicalpapers/link-budget.pdf.

2018b. Product Manual: CR6 Measurement and Control Datalogger. Logan, Utah: Campbell Scientific, Inc., 1219. https://s.campbellsci.com/documents/us/manuals/cr6.pdf.

Canary Systems. 2018. “MLWeb Software User's Guide.” New London, NH, March. http://canarysystems.com/nsupport/MLWeb_Usersguide_2017.pdf.

Chu, Lan Jen. 1948. "Physical Limitations of Omnidirectional Antennas." Journal of Applied Physics (American Institute of Physics) 19(12):1163-1175. doi:10.1063/1.1715038.

ERDCpedia. 2016. https://wiki.erdc.dren.mil/Research_and_Development_Environment_(RDE).

National Geodetic Survey (NGS). 2018. "North American Vertical Datum of 1988 (NAVD 88).” National Geodetic Survey. Website. https://www.ngs.noaa.gov/datums/vertical/north-american-vertical-datum-1988.shtml

Onset Computer Corporation. 2018. "HOBO U20 Water Level Logger.” Product Manual. Bourne, MA. https://www.onsetcomp.com/files/manual_pdfs/12315J\%20U20\%20Manual.pdf.

. n.d. Water Level Data Loggers. https://www.onsetcomp.com/products/dataloggers/water-level.

USACE (U.S. Army Corps of Engineers). 2010. Fact Sheet: Moose Creek Dam Interim Risk Reduction Measures. Joint Base Richardson-Elmendort, Alaska, 0105. https://www.poa.usace.army.mil/Portals/34/docs/engineering/FactSheetforMooseCreekDam.pdf.

Wilson, Stanley D., and R. Squier. 1969. "Earth and Rockfill Dams." Proceedings of the 7 th International Conference on Soil Mechanics and Foundation Engineering,. Mexico City: International Society for Soil Mechanics and Geotechnical Engineering. pp 137-220. https://www.issmge.org/uploads/publications/1/38/1969_04_0003.pdf.

\section{Uncited work}

Dulaney, Emmett, and Chuck Easttom. 2018. CompTIA Security+ Study Guide: Exam SYo-501, Seventh Edition. Indianapolis, IN: John Wiley \& Sons, Inc. 


\section{Acronyms and Abbreviations}

\begin{tabular}{|c|c|}
\hline $\begin{array}{l}\text { Term } \\
\text { ACE-IT }\end{array}$ & $\begin{array}{l}\text { Definition } \\
\text { U.S. Army Corps of Engineers-Information Technology }\end{array}$ \\
\hline Ahr & Amp-hour \\
\hline ANSI & American National Standards Institute \\
\hline CRREL & Cold Regions Research and Engineering Laboratory \\
\hline CRREL-APO & Cold Regions Research and Engineering Laboratory, Alaska Projects Office \\
\hline CSI & Canary Systems Inc. \\
\hline $\mathrm{dB}$ & Decibel \\
\hline $\mathrm{dBd}$ & Decibel related to dipole antenna \\
\hline $\mathrm{dBm}$ & Decibel-Milliwatts \\
\hline DMZ & Demilitarized Zone \\
\hline ERDC & U.S. Army Engineer Research and Development Center \\
\hline ERDC-CRREL & $\begin{array}{l}\text { Engineer Research and Development Center, Cold Regions Research and } \\
\text { Engineering Laboratory }\end{array}$ \\
\hline ID & Identification \\
\hline IT & Information Technology \\
\hline LoS & Line-of-Site \\
\hline MAS & Multiple Address System \\
\hline $\mathrm{MHz}$ & Megahertz \\
\hline MJ & megaJoules \\
\hline NAC & Network Access Control \\
\hline NGS & National Geodetic Survey \\
\hline NSN & National Supply Number \\
\hline Prx & receiver power \\
\hline PVC & Polyvinyl Chloride \\
\hline RDE & Research and Development Environment \\
\hline $\mathrm{Rf}$ & Radio Frequency \\
\hline SAR & Same As Report \\
\hline SF & Standard Form \\
\hline SQL & Structured Query Language \\
\hline TOC & Top of (PVC) Casing \\
\hline TR & Technical Report \\
\hline USGS & U.S. Geological Survey \\
\hline Vdc & Voltage Direct Current \\
\hline VM & Virtual Machine \\
\hline VPN & Virtual Private Network \\
\hline
\end{tabular}




\section{Unit Conversion Factors}

\begin{tabular}{|l|l|l|}
\hline Multiply & By & To Obtain \\
\hline feet & 0.3048 & meters \\
\hline BTU/square foot $\left(\mathrm{BTU} / \mathrm{ft}^{2}\right)$ & 88.0550 & megajoules $/$ square meter $\left(\mathrm{MJ} / \mathrm{m}^{2}\right)$ \\
\hline
\end{tabular}




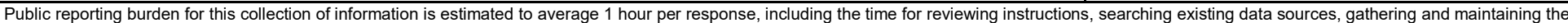

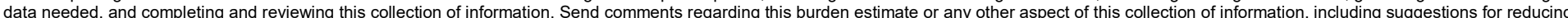

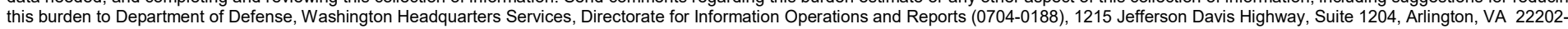

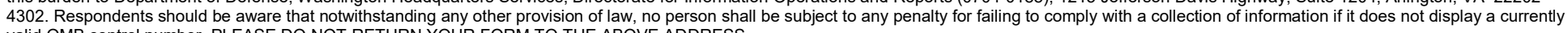
valid OMB control number. PLEASE DO NOT RETURN YOUR FORM TO THE ABOVE ADDRESS.
1. REPORT DATE (DD-MM-YYYY)
2. REPORT TYPE
$12 / 01 / 2019$
Final Technical Report (TR)

\section{TITLE AND SUBTITLE}

Web-Based Monitoring of Piezometers for the U.S. Army Corps of Engineers Moose Creek Dam, North

Pole, Alaska

6. AUTHOR(S)

Arthur Gelvin, Christopher Williams, and Stephanie Saari

\section{DATES COVERED (From - To)}

5a. CONTRACT NUMBER

5b. GRANT NUMBER

5c. PROGRAM ELEMENT

5d. PROJECT NUMBER

5e. TASK NUMBER

5f. WORK UNIT NUMBER

8. PERFORMING ORGANIZATION REPORT NUMBER

ERDC/CRREL TR-19-26

U.S. Army Engineer Research and Development Center (ERDC)

Cold Regions Research and Engineering Laboratory (CRREL)

72 Lyme Road,

Hanover, NH 03755-1290

\section{SPONSORING / MONITORING AGENCY NAME(S) AND ADDRESS(ES)}

U.S. Army Corps of Engineers Alaska District

P.O. Box 6898

JBER, AK 99506-089
10. SPONSOR/MONITOR'S ACRONYM(S)

11. SPONSOR/MONITOR'S REPORT NUMBER(S)

\section{DISTRIBUTION / AVAILABILITY STATEMENT}

Approved for public release; distribution is unlimited.

\section{SUPPLEMENTARY NOTES}

This work was funded via Interagency Agreement No. DTFH7016X300oo8

\section{ABSTRACT}

The Moose Creek Dam, completed in 1979, is a 7.5-mile long earthen dam located in North Pole, Alaska designed to protect the Fairbanks and North Pole areas from flooding by regulating flow on the Chena River. The earth-filled embankment and a concrete control structure regulates flow with four gated bays. In 2014, two minor flood events took place within 1 month of each other. Flood observations discovered over 1,00o pin/small sand boils downstream of the stability berm, which could signify the initiation of backward erosion and piping with a vertical exit through the boil. The location of greatest distress was mostly within areas of permafrost, some of which have degraded since the dam's construction. During operation, groundwater levels are measured manually at more than 150 piezometers. In 2018, the Corps of Engineers Alaska District tasked the Cold Regions Research and Engineering Laboratory (CRREL) to automate-groundwater levels measurement by installing 21 piezometers. CRREL added instrumentation and monitoring to a network system that aggregates all data. The web-based monitoring system provides a new tool that allows remote Corps personnel to monitor groundwater levels and seepage in areas of significant concern and receive notifications of developing distress during a flooding event.

\section{SUBJECT TERMS}

Piezometer, Remote sensing, Groundwater, Water table, Earth dams--Erosion, Earth dams--Seepage, Chena River (Alaska)

\section{SECURITY CLASSIFICATION OF:}

\section{a. REPORT}

Unclassified

\section{b. ABSTRACT \\ Unclassified}

\section{c. THIS PAGE}

Unclassified

.

17

18. NUMBER OF PAGES

OF ABSTRACT

SAR
60 19a. NAME OF RESPONSIBLE PERSON

19b. TELEPHONE NUMBER (include area code) 